\title{
A Goldfish Notch-3 Homologue Is Expressed in Neurogenic Regions of Embryonic, Adult, and Regenerating Brain and Retina
}

\author{
STEVEN A. SULLIVAN, LINDA K. BARTHE L, BRIAN L. LARGENT, AND PAMELA A. RAYMOND* \\ Program in Cell, Developmental, and Neural Biology, Department of Anatomy and Cell Biology, \\ University of Michigan, Ann Arbor
}

\begin{abstract}
Members of the $\mathrm{N}$ otch gene family are thought to be involved in the regulation of cell fate decisions in a variety of embryonic tissues, particula rly in the developing central nervous system (CNS) in Drosophila and vertebrates. In goldfish the C N S continues to develop and add neurons well into adulthood and has the capacity to regenerate new neurons. Using probes derived from Xenopus $\mathrm{N}$ otch to screen an adult goldfish retinal cDN A library, followed by 5' RACE, we isolated a partial CDNA for a goldfish Notch homologue, $G-N$ otch. Sequence a lignment sup ported a ssignment of $\mathrm{G}-\mathrm{N}$ otch to the $\mathrm{N}$ otch-3 class. N orthern blot analysis revealed a single transcript of $>8 \mathrm{~kb}$, and $\mathrm{RN}$ ase protection assays indicated that $\mathrm{G}-\mathrm{N}$ otch is expressed in eye and brain but not muscle of adult goldfish. The spatiotemporal pattern of expression of $\mathrm{G}-\mathrm{N}$ otch was defined from early embryonic stages to adulthood by in situ hybridization. Expression in the embryonic C N S was localized to neurogenic regions and was downregulated in differentiated cell populations. In adult goldfish, expression persisted in and adjacent to the germinal zones in the retina and the brain. W eak expression was seen in scattered cells in the inner nuclear layer of the retina, which might include neurog enic stem cells. Follow ing retinal lesions (puncture wounds or laser lesions restricted to photoreceptors in the outer nuclear layer), $\mathrm{G}-\mathrm{N}$ otch was upregulated in proliferating cell populations throughout the retina, in association with a genera lized mitogenic response. In the region of the la ser lesion, where ea rlier studies have demonstrated that photo receptors a re regenerating at $1-3$ weeks following the lesion, $\mathrm{G}-\mathrm{N}$ otch expressing cells were abundant in the outer nuclear layer. These observations suggest that retinal regeneration involves the re expression of an important developmental signaling molecule in neuroepithelial cells resident in the differentiated retina. Dev. G enet. 20:208-223, 1997. (c) 1997 W iley-Liss, Inc.
\end{abstract}

Key words: cell fate; neurogenesis; regeneration; retina; photoreceptors; optic tectum

\section{INTRODUCTION}

Vertebrates that grow continuously and have the capacity to regenerate could provide convenient models for defining factors involved in determining cell fates in the central nervous system (CNS). Goldfish and other teleosts displaying indeterminategrowth maintain neuronal progenitor cells throughout their lives [Müller, 1952; Richter and Kranz, 1970a,b; J ohns, 1977; Meyer, 1978; Raymond and Easter, 1983], and can regenerate CNS tissues [K irsche, 1960; Kirsche and Kirsche, 1961; Richter, 1968; Richter and Kranz, 1977; Maier and Wolburg, 1979; Raymond et al., 1988; Hitchcock and Raymond, 1992].

Thegoldfish retina contains several distinct, proliferative cell populations in the neuroepithelial lineage. Most neurogenesis occurs in the germinal zone (GZ), an annulus of proliferative neuroepithelial cells at the ciliary (iris) margin [Müller, 1952; J ohns, 1977; Meyer, 1978]. Another site of neurogenesis is the outer nuclear layer, where scattered proliferative "rod precursors" maintain the density of rod photoreceptors (and hence visual sensitivity) by interstitial addition of new rods [Raymond and Rivlin, 1987; Powers \& al., 1988]. Although the cellular fate of rod precursors is normally restricted, they are thought to be pluripotent and have been implicated in the regeneration of all neuronal cell

Received 11 October 1996; accepted 2 December 1996.

*Correspondence to: Dr. Pamela A. Raymond, Department of Anatomy and Cell Biology, University of Michigan, 4610 Medical Science II Bldg., Ann Arbor, MI 48109-0616; E-mail: praymond@umich.edu

Contract grant sponsor: National Institutes of Health; Contract grant number: EY04318.

Brian L. Largent is now at Dupont Merck Pharmaceutical Company, Experimental Station, P.O. Box 80400, Wilmington, DE 19880-0400.

Steven A. Sullivan is now at the Department of Anatomy, George Washington University, 2300 I Street NW, Washington, DC 20037. 
types in damaged retinas [Raymond et al., 1988; Hitchcock et al., 1992]. Müller glia derive from the same multipotent neuroepithelial progenitors that generate retinal neurons [Turner and Cepko, 1987]. Although normally quiescent, they become mitotic after retinal damage [Wagner and Raymond, 1991; Lewis et al., 1992; Braisted et al., 1994], but there is no direct evidence that they transdifferentiate into neurons. Finally, undifferentiated, very slowly dividing cells scattered throughout the inner nuclear layer have recently been identified in the retina of adult fish, and may constitute a retinal stem cell population [Braisted et al., 1995; J ulian and Korenbrot, 1996; Raymond and Hitchcock, 1997].

Proliferating neuronal progenitor populations and the ability to regenerate neural tissue are also characteristics of the adult goldfish brain. The optic tectum, for example, contains a multipotent germinal zone [Kirsche and Kirsche, 1961; Meyer, 1978; Raymond and Easter, 1983] and constitutively di viding populations of ependymal and radial glia [Stevenson and Yoon, 1980, 1981, 1982; Raymond and Easter, 1983].

Although studies using goldfish have yielded abundant information about the cellular aspects of neural development and regeneration, molecular characterization of these processes is rudimentary. Our strategy has been to pursue conserved genes that may play similar roles in analogous developmental events across evolution. For example, an early devel opmental event common to insects and vertebrates is the segregation of neural progenitors from within a field of equipotential "proneural" cells by a process of lateral specification [Artavanis-Tsakonas et al., 1995; Simpson, 1995; Chitnis et al., 1995]. This process is thought to be driven initially by small, possibly random intercellular differences in levels of expression of the transmembrane receptor Notch and its transmembrane ligand Delta, products of genes first characterized in Drosophila. Delta, expressed by a putative neural progenitor, binds to the extracellular domain of Notch on a neighboring cell, activating a signaling pathway that represses the activity of proneural transcription factors, as well as Delta expression itself, in the Notch ${ }^{+}$cell [J ennings et al., 1995; Chitnis and Kintner, 1996]. Small differences in levels of Notch and Delta expression are thereby amplified so that ultimately a single cell within a proneural cluster commits to a neural fate, while its neighbors remain uncommitted and competent to participate in subsequent episodes of differentiation [Chitnis et al., 1995].

The first characterized vertebrate Notch transcript, cloned from a Xenopus cDNA library, was shown to be expressed strongly in the embryonic neuroepithelia, including the germinal zone of the developing Xenopus retina [Coffman et al., 1990]. Rat Notch cDNAs cloned subsequently also showed embryonic retinal expression [Weinmaster et al., 1991, 1992]. Notch therefore seemed a good candidate for a gene that would be involved in the neurogenetic processes occurring in the embryonic and adult teleost CNS during both development and regeneration. We report here the cloning of a partial CDNA for a goldfish Notch homologue (G-N otch) which is expressed in neural progenitor populations through adulthood, and whose expression is enhanced and its pattern altered in the retina after injury and during photoreceptor regeneration.

\section{MATERIALS AND METHODS}

All standard molecular biology techniques are according to Sambrook et al. [1989] unless otherwise indicated. Stages of goldfish embryonic development are according to Kajishima [1960].

\section{Isolation of G-Notch CDNA}

An oligo d(T)-primed $\lambda$ gt10 cDNA library (gift of Dr. Daniel Goldman), made from goldfish retinal $\operatorname{poly}(A)^{+}$ collected 10 days after optic nerve crush, was screened at low stringency with random-primed probes derived from the coding region of a X-N otch-1 CDNA clone (gift of Dr. William Harris). Final stringency washes were in $2 \times \mathrm{SSC} / 1 \%$ sodium dodecyl sulfate (SDS) at $55^{\circ} \mathrm{C}$. Purified positive plaques were assayed by polymerase chain reaction (PCR) for the presence of a highly conserved $\sim 600$ bp cdc10/ankyrin (ANK) repeat region of Notch, using degenerate primers based on the N otch/ $X-N$ otch-1 ANK repeat region flanking peptides TPLMIA and ITDHMD: ([ECORI site underlined] 5'-CAGAATTCACXCCXYTXATGATHGC-3'; [HinDIII site underlined] 5'-ACAAGCTTRTCCATRTGRTCXGTDAT-3; $D=G / A / T, \overline{H=A / C / T}, R=A / G, X=G / A / T / C)$. Degenerate PCR cycle conditions were $94^{\circ} \mathrm{C} 3 \mathrm{~min}$, followed by 30 cycles of $\left(94^{\circ} \mathrm{C}, 30 \mathrm{sec}\right) /\left(44^{\circ} \mathrm{C}, 30 \mathrm{sec}\right) /$ $\left(72^{\circ} \mathrm{C}, 60 \mathrm{sec}\right) ;\left[\mathrm{MgCl}_{2}\right]=2.5 \mathrm{mM}$. This screen identified a 2056 bp clone (GotchCDC) encoding most of the intracellular region of a goldfish Notch homologue. Weakly conserved sequences at the $5^{\prime}$ end of GotchCDC (5'-CCACTGTCTGCTGTCAACTG-3' , = AVDSRQW; 5'CATCCTCACCATCAGACAGA-3' = LSDGED) were used as nested primers in a commercial 5' RACE protocol (Promega, Madison, WI) to amplify and sequence 2372 bp of upstream sequence (GotchTM) from stage 19 embryonic goldfish RNA. RACE PCR conditions were $94^{\circ} \mathrm{C}, 3 \mathrm{~min}$, followed by 30 cycles of $\left(94^{\circ} \mathrm{C}\right.$, $30 \mathrm{sec}) /\left(57^{\circ} \mathrm{C}, 30 \mathrm{sec}\right) /\left(68^{\circ} \mathrm{C}, 8 \mathrm{~min}\right),\left[\mathrm{MgCl}_{2}\right]=2 \mathrm{mM}$. Sequencing was done both manually and with the use of an ABI automated sequencer (Applied Biosystems, Foster City, CA) by using primer walking and nested deletion methods. Fragments were completely sequenced in both directions and were assembled by MacVector (IBI, New Haven, CT) and Sequencher (Gene Codes, Ann Arbor, MI) software. Conceptual assembly of GotchCDC and GotchTM yielded a single open reading frame, referred to as G-Notch in this paper. GotchCDC and GotchTM are deposited in GenBank under the accession number U 09191. 


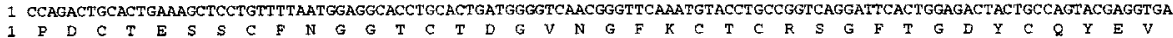
116 ACAATTGTGACTCTCAGCCATGCCTTAATGGAGGAGTGTGTCAAGATGCCCTCGATCATATCOCTGCTCGTGTCCAAAAGGCTACTCTGGCCCCGTTGCCAGTATCCAGTTGA

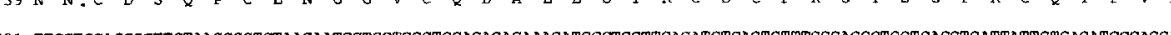
231 TTGGTGCAGGCCTTCTAACCCGTGTAAGAATGGTGGTCGCTGCAGACAGAAAGATGCCTCCTTCACATGTGACTGTTTGGGAGGCTGGTCAGGTCATTATTGTGACATCCCAGGA 346 GTGGCTTGTGAGGTTGCAGCCAGACAGAGAGGACTCCAAACAGATCAGCTTTGCACCATGGTGGACACTGCGTCAATACTGGCAACACGCACTACTGCAAATGTCCCGCTGATT

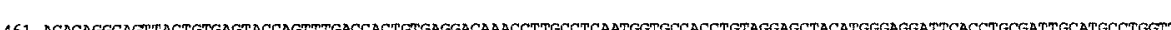

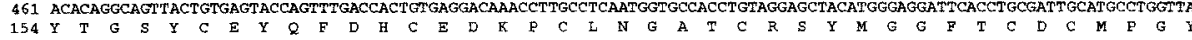
576 TGAGGGGGACAACTGCGAGAGAGAGGTCAATGAGTGTCAGTCTCATCCGTGTCAGAATGGAGGAACCTGCATTGACCTGGTGGGACATTACATCCGCTCCTGCCCTCCAGGCAC

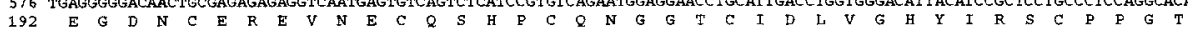
691 CTGGGGGTCCTCTGTGAGATAAATGGGGATGACTGCGCAACTCCCTCATGGCCTCGGGGCATGCCCAAGTGTCAAAACAATGGCACCTGTGTGGACACGGTTGGAGGGTACAGG 231 L G V L C E I N G D D C A $T$ T $P$ S $S$ W 806 GTAACTGCCCTCCCGGCTTCACTGGAGAACGCTGTGAGGGATACATCAACGAGTGCCTTTCGAACCCCTGCAAAACCTCCAACAGCTTGGATTGCATACAGTTGCCAAATGATTA

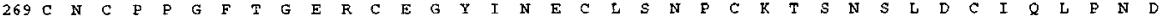
921 CCAGTGCATGTGCAAACCCGGATTCACAGGACAAGGGTGTCAGAATAGATTTAGTGTGTGCGATCTCAGCCTTGTAAAACGAAGGAGTATGCTCCTTGTCCAGCAGCTCGCCA
307 1036 CTGGAATACACTTGCACCTGTCAGCTTGGGTACGCAGGTGCTAACTGTGAGAGGAGCATGAACTGCAAAGAGCTGCCTTGCTACAATGGTGGGAGCTGTAGTGATACCTCACGA 346 I

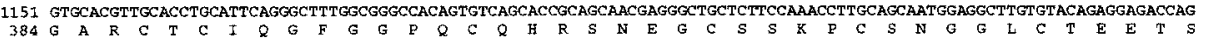
1266 CTTCCCTTPTTTCCACTGCCAGTGCATCAGTGGCTGGAAGGGGATCCGATGTGAACAGGAAACAAGGGCTTTGCCCCATTGCCCTATTGCTGAATGTCATGGCAAGGCCAATGAC 422 F P F F H C Q C I S G W K G I R C E Q E T R A L P H C P I A E C H G 1381 GGTGTGTGTGATAAAGAATGTAATTCGCTTGCCTGCCGCPGGGATGGAGGTGACTGCTCTCTGGCTATGAACCCCTGGGCACGCTGCTCAGACCCTCGCTGCTTGCGGCTTTTC 1496 ACAATAGTCAATGTGATGAGTTCTGCAACAATGCTGAGTGCCTGTATGATAACTTTGACTGCAAGAACAAAGAGAAAGTCTGCAACCCCAMCTACGAGACATACTGTACAGACC

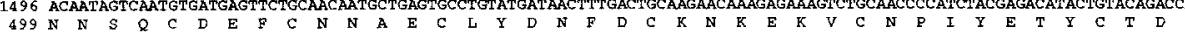
1611 TTACACAGATGGGCTCTGCGATCAAGGCTGCAATACTGAAGAGTGTGGCTGGGATGGACTGGATTGTGCAAAGAAGATTCCAGAAGACCTTGCGGAAGACCTGCTGGTTGTTGT 537 Y $T$ T $D$ D G L 1726 GTTCTGCTGCCTCCCGAGGAGCTGCTAAGGACAAAACTGCTTTCCTGCAAAGACT TAGTGCAATACTGCACACCACATTGCGTTTTCGCCITGA 1841 TCAAACCCTATAAAGGACATGGGAAACGCAGTAAACGGGAGCTTCAACCTCAGCAAGAGGTTATTGGGTCTATTGT ATACTTGGAAATAGACAACAGGCTCTGCTCCCAAGGTT

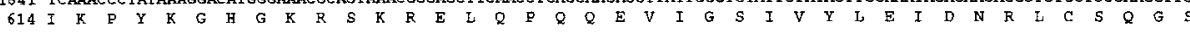
1956 AAATGACTGTPTCGGAATGCTAGCAGTGCTGCAGAATACCTAGGTGCTTTGTCTGTTAGGGGATGTTGAATTTCCCATACCCCCTGAAAGAAGTGCGCAGTGAATATAAGAAA 2071. CCGATTGAAGTTATTCCCGAATGGGGTAAACTACTGCTAGTAGGAGTAGCTTCTCTCCCCTTGTTGGTTATCTTGATGGTGGGCATGTTGATTGCCCGCCGCAAACGTGAACACA 691 E I $\quad$ E V V I I F 2186 GCACACTCTGGTTCCCTGAGGGCTTCTTCCTCAAGAAGGAAACAAGCAGTAACAAGAACCGCAGAGAACCTGTGGGCCAAGATTCCCTGGGCATGAAACGCATGCCAAAGACAG 729 S T T L W F 2301 GGAAGAGTCTCITTTGGCAGATCACAGTGACCAGTGGATAGACACAGACT GCCCAGAGGCAAAACGMACTTAATGGTGGAGAGCCCAGTATTCTGTCTGATGGTGAGGATGCAGTT GotchCDC

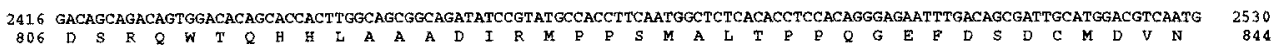
2531 TCCGAGGCCCTGATGGCTTCACACCCCTGATGCTGGCATCCTTCTGTGGAGGTGGGCTGGAGCTAGAGGTGACCGAAGATGATGATTCAGAAGAATGTTCCGCCAACATCATATC 2645

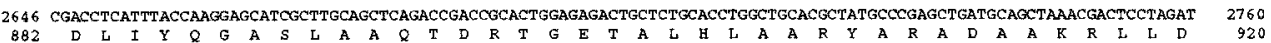
2761 GCTGGGGCTGATGCAAATGCACAGGATAACACAGGCCGCACACCTCTGCATGCAGCTGTAGCAGCTGATGCACAGGGGGTTTTCCAGATTCTGATCAGGAATCGTGCCACAGACC 2875 921 A G A A A N A Q 2876 TGGATGCACGCATGTATGATGGCTCCACTOCTCTGATCCTTGCAGCCCGTCTGGCAGTAGAAGGCATGGTGGAAGAGTTGATCACCTGTCATGCAGATGTCAACGTTGTTGATGA 2990

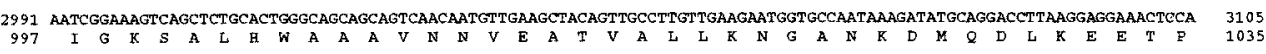
3106 CTATTCTTGGCTGCCAGGGAAGGTAGCTGTGAGGCTGTAAAGGTGTTGTTGGCTCACTTTGCCAACAGGGAGATAACGGATCACATGGACAGGCTTCCTCGAGATATCGCGCAG

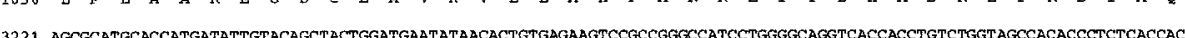
1074 E $R$ R 3336 CATGTGTCCTCCCAGCAACTTCCTCCAAGGGCTAAAAAGCACCCCACAGGGTAAGAAGAACCGTCGCCCAGGGTTTAAGGCATAGGTGGGCAGCACGCTACAAGCCTGAAAGA $1112 \quad M \quad C C$ P 3451 TCAGCCAAAGGACGCAACAAACGGCTGTCGCTTGACATGCAGAGTGCTTTGCTGGAGAGCTCTGTCACGCTCTCCCCCGTCGACTCGCTGGATTCGCCACGTGGAGGTGCCAGC 3566 ATGCCGGCTACATCCCCAATCCGACCTCACCGGCCGCCATGCCCTCCCCAGGCCTTTTCCACTCCTCCATGTCTGTCCCATCCACTCCAATGGTGCACAGCAGTATCTTGGATGC 1189 N A 3681 CACCAGTCCTTTTGCAGTCTCCCTAGCTCAGCTGAGCGACCTGAGTGATGGTGGGCTCTCCATGCAGGGGCGTGTGGCCATGCAAGGAGGCGGCATCAACCAAGGCCTCACAAC 1227 T $S$ S F F 3796 TGTGTGCTGAACGCCGGCCAGATGAGCCTCAACATGGGCATGGTAAGTCCAGTAAGCGTGCCATT TGACTGGCACAACCGCATGCCTCCATCTTCTCAGAGCTGTCAGTCCATGG 1266 C V L A G O S L N M G M V S P V S V P F D W A N R M P

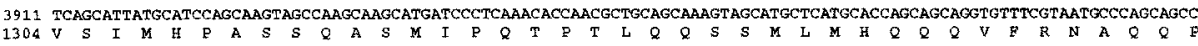
4026 CATCCTGCAGCCGACACCCGTCTCCAACACACCCTCTATTAGCCCGGTCAAACTGCCGTCCATTGCAGAGCAGCAGCCACAGCAACTTCACAGCCACOCCCITACCAACCCAAA 4141 CACACCCGCATGAGCTCCTCCACTCCCCCGACCCCACAACAGGCACAGCCTCCTCCAGCTTTCTACCAGCCACAGCAGCCACAGACTCAGCCACCGCAGGCCTCGGCAGCCCCTC

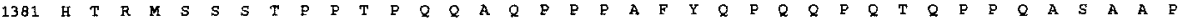
4256 AGGCTTCGCAAGCACAGGCTATCCCATCTCAGGCACTCCCGGCACAGGCGAGCGTAAGCACCGCAGGCCCGGAGGATTACCCCACACCGCCCTCCCAGCACAGCTACAGCTCTGC 1419 Q A $S$ S \& A $\&$ A 4371 CATGGATGCGACACCCAAGCATTACCTGCATGTGCCCAGTGAACATCCTTACCTGACC

Fig. 1. DNA sequence and conceptual translation of G-Notch. The region of overlap between the component GotchCDC and GotchTM CDNAs is boxed. 


\section{R Nase Protection}

A 233-bp BstEII restriction fragment of G-Notch corresponding to bp 2372-2605 (aaVEEP...LEVT) served as a template for synthesis of ${ }^{32} \mathrm{P}$-labeled antisense RNA probes for RNase protection assays of total RNA from adult brain, retina, and flank muscle, performed according to manufacturer's protocols (Ambi on, Austin, TX). Following electrophoresis, the gel containing protected fragments was dried onto Whatman paper and exposed to Kodak XAR film (Eastman Kodak, Rochester, NY) for $15 \mathrm{hr}$ at $-70^{\circ} \mathrm{C}$ with two intensifying screens.

\section{Northern Blot}

Total RNA was isolated from goldfish brain using Trizol Reagent (Gibco BRL, Grand Island, NY) according tothemanufacturer's instructions. Samples containing 10, 25, and $50 \mu \mathrm{g}$ total RNA were mixed with sample buffer [Sambrook et al., 1989] and denatured at $68^{\circ} \mathrm{C}$, for $10 \mathrm{~min}$. RNA was el ectrophoresed at $40 \mathrm{~V}$ for $4 \mathrm{hr}$ at room temperature in a 1.0\% agarose/1× MOPS/ $0.22 \mathrm{M}$ formaldehyde gel [Tsang et al., 1993], transferred to nyl on membrane (Boehringer Mannheim, I ndianapolis, IN) by downward neutral pH capillary transfer with 20× SSC [Chomczynski and Mackey, 1994], and ultraviolet (UV)-cross-linked (Stratalinker, Stratagene, LaJ olla, CA). Digoxigenin-labeled antisense RNA probes were prepared from GotchCDC and GotchTM plasmids with the Genius System (Boehringer Mannheim, Indianapol is I N). The two probes were combined (each at 100 $\mathrm{ng} / \mathrm{ml}$ ) and hybridized according to the manufacturer's instructions, except the high-stringency wash was at $68^{\circ} \mathrm{C} / 0.1 \times \mathrm{SSC} / 0.1 \%$ SDS. Detection was with the CSPD chemiluminescent substrate (Boehringer Mannheim), and the blot was exposed for $30 \mathrm{~min}$ to LumiFilm (Boehringer Mannheim).

\section{Retinal Lesions}

Goldfish (Carassius auratus), obtained from a local pet store or from Ozark Fisheries (Stoutland, MO) were anesthetized with $0.2 \%$ tricaine methanesulfonate, and the eyes were punctured multiple times through the sclera with an acupuncture needle [Sullivan and Raymond, 1991]. The fish were allowed to survive up to 15 days after the lesions.

An argon laser (System 920, Coherent, PaloAlto, CA) was used to produce retinal lesions as previously described [Braisted et al., 1994]. Briefly, fish wereanesthetized, thelens was removed through a slit in the ventral edge of the cornea, and the cornea was all owed to heal without suturing for 2-3 weeks. To improve the optics, a drop of methyl cellulose was applied to the cornea, and the retina was visualized with a slit lamp. Lesions (4 per retina) were produced with laser pulses using settings of $130 \mathrm{~mW}, 0.1 \mathrm{sec}$, and $500-\mu \mathrm{m}$ spot diameter. The cell loss produced by the laser at these settings was confined primarily to the photoreceptor layer [Braisted

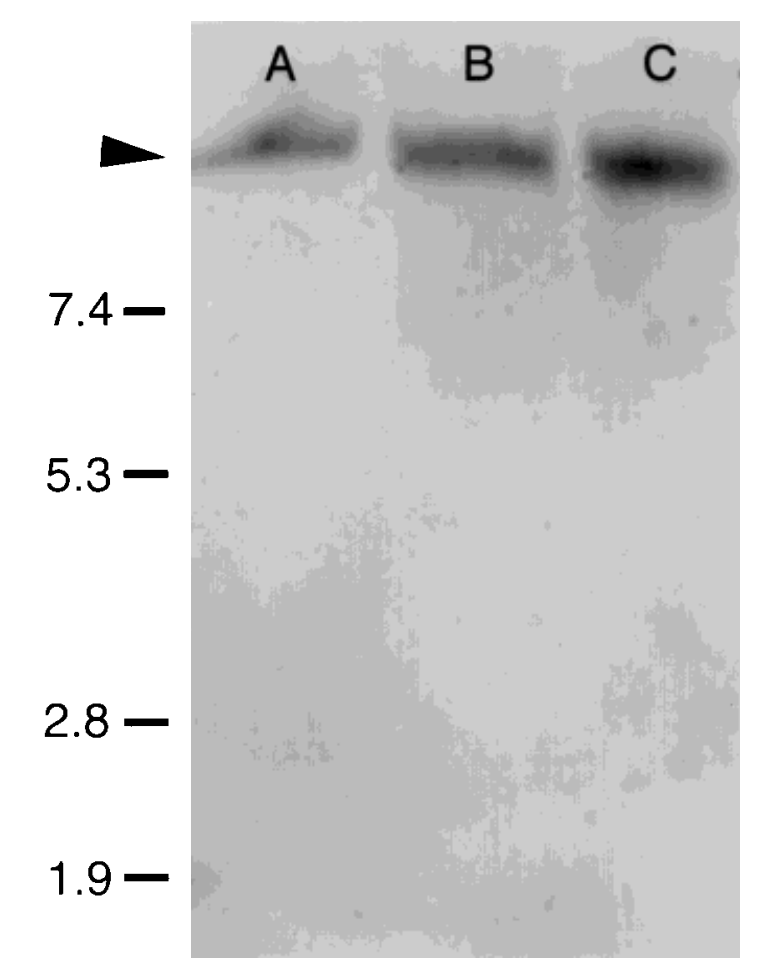

Fig. 2. Northern blot of goldfish brain RNA hybridized to an antisense RNA probe transcribed from GotchCDC and GotchTM. Lanes A,B,C, 10, 25, and $50 \mu$ g total RNA loaded, respectively. A single band of 8.5-9.0 kb hybridized to the probe (arrowhead).

et al., 1994]. Fish survived for 1 day to 4 weeks following the lesions.

In some cases, proliferating cells were labeled with bromodeoxyuridine (BrdU) injected intraocularly, to achieve an approximate intraocular concentration of 50 $\mu \mathrm{M}$, at $24 \mathrm{hr}$ prior to retinal fixation, as described previously [Barthel and Raymond, 1993; Braisted et al., 1994].

\section{Tissue Preparation, In Situ Hybridization, and I mmunocytochemi stry}

GotchCDC and GotchTM plasmids were used to generate sense and antisense RNA probes labeled with digoxigenin (DIG)-UTP (Boehringer Mannheim) or ${ }^{35} \mathrm{~S}$-UTP. Results were identical using either template. Retinas were fixed for $1-3 \mathrm{hr}$ in $4 \%$ paraformalde hyde $/ 5 \%$ sucrose in phosphate-buffered saline (PBS) (pH 7.4). Tissue preparation, BrdU immunocytochemistry and nonradioactive in situ hybridization of whole embryos and secti ons was performed as described previously [Barthel and Raymond, 1993; Raymond et al., 1995], except that 5- $\mu$ m-thick cryosections were treated with proteinase $K$ for $2 \mathrm{~min}$, $45 \mathrm{sec}$. The DIG-labeled probes were visualized with a colorimetric alkaline phosphatase reaction using the substrate 5-bromo-4chloro-3-indolyl phosphate with 4-nitroblue tetra- 
A

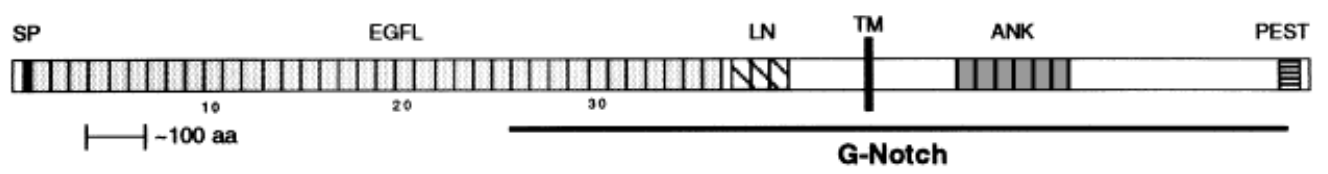

B

M-Notch-3

*EGPL26

EGPL27 - DGFL28

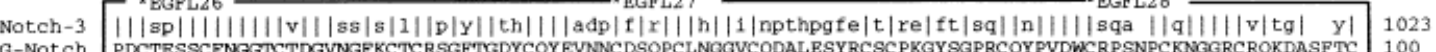

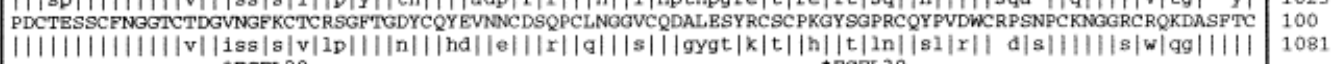
FERL 29 BGPL 30

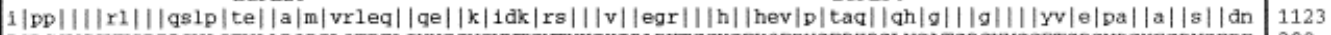
DCLOGWSCHYCDI PGVACEVAARQRGLQTDELCHHGGHCVNTGNTHYCKCPADYTGSYCEYQFDHCEDKPCLNGATCRSYMGGFTCDCMPGYEGDNCERE 200 q|as||t|1|||v|s|s|||||||q|vsvav||r|a|q||da||||l|r|q|g||||||qe|v|e|qpn||q|||||td|1||ys|e|v|||h|m||sk| 1181

1d||a|q||||||s|||||ar|1c||||||||||||||e|||a1gps1 dsgvq|1h||||||1|||f|||||||r||1h||ad||||rpga|haahtr| 1222 VNECQSHPC QNGGTCIDLVGHYIRSCP PGTLGVLCEINGDDCATPSWP RGMPKCQNNGTCVDRVOGYRCNCPPGFTGERCEGYINECLSNPCKTSNSLD 299 1|||1|q||l|||||||||nt|kc|||r||q||h|||di||lspsvd|lt|e|r|f|g|r||||||||g|v||a||v||||||dv|||||d||dD|g|rn 1281 |1|d|gghfr|v|h|||||pr||1al|p||||||qhg|q|rh||grggg|tf||h|vppfw|lr|||vars|r||q|pv|1p|qq|a||p||a|pp|1s| 1322 CIQLPND YQCNCKPGFTGQGCQNRF SVCESQPCKNEGVC SLSSSSPLEYTCTCQLGYAGANCER SMNCKELPCYNOGSCSDTSRGARCTCIQGFG 395

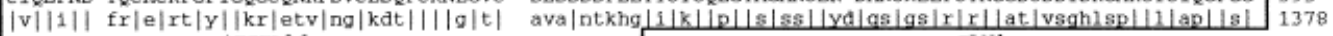
|s|rvsraspsgat.as|a|a||lh||s|lpvq|v|||r|v|ap||g|p|| |tpsaap|vpee|r||r|a|qa|rg|qn||r|||tpg|g 1412

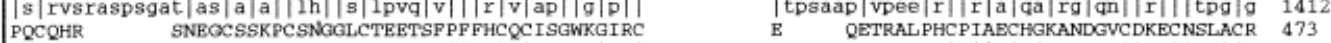

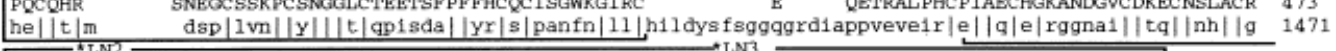
||||||||nvdd||rq|eal q|w||||||r||pa|sspa||||||||ysggrart|||v||k||a||fa||r||||||||||||||||||sev|al||r 1511 WDGGDCSLAM NPWARCSDP RCLRLFNNSQCDEFCNNAECLYDNFDC KNKEKVCNPIYETYCTDHYTDGLCDQGCNTEECGWDGLDCAKKIPEDLAE 569 ||||||||ntad||qn||aalq|w|y||dgk|||q|at|g||||g||| grl|gq|||1|dq||r|||a||h||||||na||e|||||||ddv|qk||v 1569

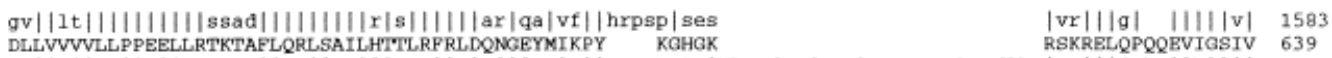
gs||1||h1||d||rnrsss||re||sl|||nvv||r|a|||al|f||ygsehe1s|hkrsdwtapgg1mgrarrs1tsf1kp|tr|||a hm||k|||| 1668 m||||||||q|aendh||pd|q|||d||||||av|r|d|||||rd||g| |1|apeqsvp||D| lvagavf||1|fi1|vmv|| |||||||||||| 1678

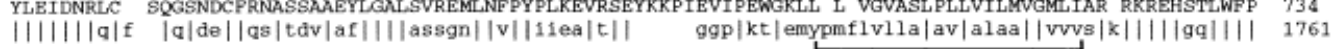

|||a|h|d1aagh|g||||||||a||||n|a| g|||mgevvtaln|se|||||||||||||gm ga|epe|c|||||||||v||||||va|at|||||||| 1774 EGPFLKKB TSSNKNRREPVGQDSLGMKRMPKTVEESLLLADHSDQWIDTDCPEAKRLKVEEPSILSDGEDAVDSRQWTQHHLAAADIRMPPSMALTPPQG 833 ||| kvnepk|k||||||e||v|l|pl |nsds||mdeqlse|aed| tn||frf|gq||| emsgql|h|||||q||a|||1|ln |||p||||| 1853

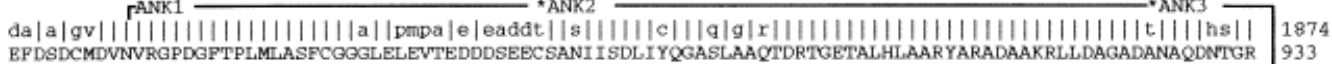
gien|||||||||||||||||1||cs|||||n|nglae |dp||dv|t|f||h||n|hn|||||||||||||||||||s|||||||esc||||v|||m|| 1951 ||$|t||t||||||||||||| s|||||||a||||||||||||||||||||||a s||||| a|||1||||||||||||||||||| 1|||||||||||||s||| \mid 1974$

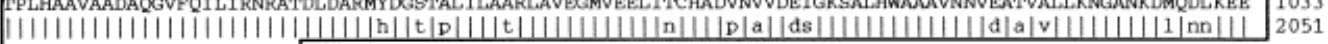

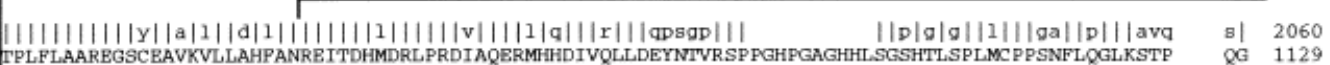

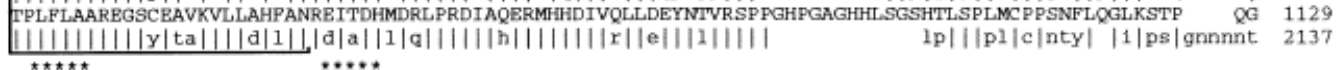

$t|| s|||p g| t g 1|p q g| \quad r|| g|k| t|a c p g p| a d|||||||||||||| \quad$ pfsgp|al|ggf|le|py a| 2130 KKOF

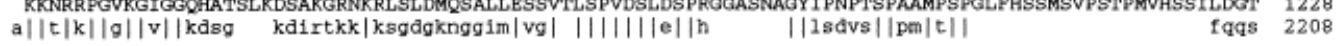

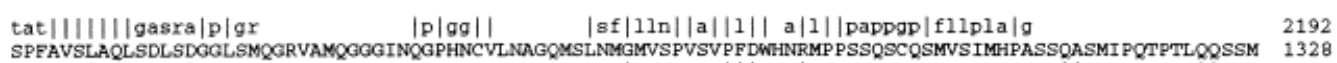

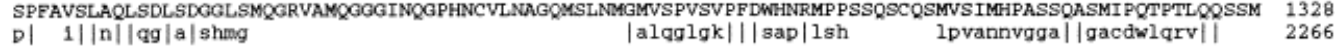

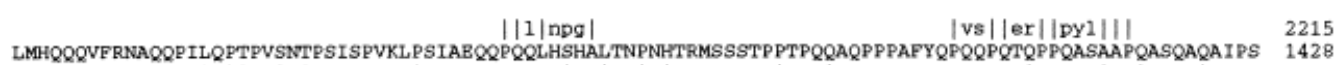

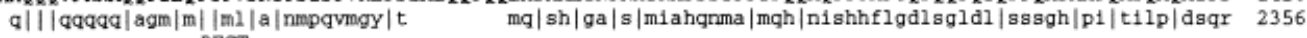
ghg|e||astrs| p|karf|r||||||||| 2246 QALPAQA
$\mathrm{m}|\mathrm{p}| 1$

Fig. 3. A: Canonical Notch protein, indicating conserved regions and region of homology to G-Notch. The latter was determined using BESTFIT (GCG Software Package, University of Wisconsin) to compare G-N otch to Notch proteins availablein GenBank. B:Alignment of G-Notch to M-Notch-3 [Lardelli et al., 1994] and Z-Notch [Bierkamp and Campos-Ortega, 1993], sequences that illustrate the overriding effect on Notch homology of phylogeny at the molecular level versus the organismic level. BESTFIT was used to determine the boundaries of the region of homology between G-Notch the other two Notch proteins as above. Multiple alignment of these regions was performed using the GCG PILEUP program. Slashes, amino acid identity to G-Notch. The conserved EGFL repeats [Davis, 1990], lin/Notch (LN) repeats, transmembrane (TM) domain, ANK repeats [Peters and Lux, 1993], and PEST (Pro/Glu/Ser/Thr-rich) domain [Rogers et al., 1986] are indicated by name in both panels. Putative BNLS sequences [Dingwall and Laskey, 1991] are indicated in the alignment by asterisks. Numerous scattered glutamine (Q) residues near the C-terminal end of G-N otch probably represent a vestigial opa polyglutamine repeat region [Wharton et al., 1985]. 
zolium chloride (Boehringer Mannheim). In some cases, whole embryos were embedded in methacrylate (Energy Beam Sciences, Agawam, MA) after in situ hybridization, and sectioned at $3 \mu \mathrm{m}$. Radioactive in situ hybridization to adult brain (10- $\mu$ m-thick cryosections) was performed as described in Hieber et al . [1992].

I mmunofluorescent detection of BrdU was performed as described [Barthel and Raymond, 1993], using a rat monodonal anti-BrdU antibody (Accurate Chemical, Westbury, NY) and a secondary antibody conjugated to Cy3 (J ackson ImmunoResearch, West Grove, PA). A rabbit polyclonal antibody (F GP2, gift from Dr. Michal Schwartz) raised against goldfish glial fibrillary acidic protein (GFAP) visualized with a secondary antibody conjugated to FITC (J ackson ImmunoResearch, West Grove, PA) was used to label Müller glia.

\section{RESULTS}

\section{I solation and Sequence Analysis of G-Notch}

An initial screen of a goldfish retinal CDNA library using Xenopus Notch-1 (X-Notch-1) probes yielded a $\sim 2-\mathrm{kb}$ clone (Gotch CDC) encoding a peptide with extensive homology to the intracellular region of $\mathrm{N}$ otch proteins. The 5' end of GotchCDC encoded a region poorly conserved between mammalian Notch orthologues. This region was used to design primers for 5' RACE to extend the sequence and confirm its identity. This strategy yielded a $\sim 2.4-\mathrm{kb}$ PCR fragment (GotchTM), from stage 19 embryonic CDNA, that was highly homologous to extracellular and transmembrane domains of N otch proteins. The region of overlapping DNA sequence between GotchCDC and GotchTM (20 bp exclusive of the RACE primer) is $100 \%$ identical between the two clones; conceptual assembly of the two clones yields a continuous open reading frame, indicating that they are part of the same transcript, hereafter referred to as G-Notch (Fig. 1). The truncated nature of the conceptual translation product, the absence of initiation and signal peptide sequences at the $5^{\prime}$ end of G-Notch, and of polyadenylation signal sequences at the $3^{\prime}$ end, all suggests that the $\sim 4.4-\mathrm{kb}$ construct represents only part of a full-length G-Notch CDNA. Hybridization of a mixture of GotchCDC and GotchTM probes to a single RNA band of $8.5-9 \mathrm{~kb}$ in adult goldfish brain (Fig. 2), lends further support to this inference.

The canonical Notch gene product is a large transmembrane protein whose extracellular domain contains a signal peptide, 36 EGF-like (EGFL) tandem repeats, and three tandem cysteine-rich lin12/Notch repeats (Fig. 3A). The intracellular domain contains six tandem cdc10/ankyrin (ANK) repeats separated from a C-terminal PEST region by a lengthy domain that is relatively unconserved apart from the presence of a putative bipartite nuclear localization signal (BNLS). G-Notch homology to other Notch proteins extends

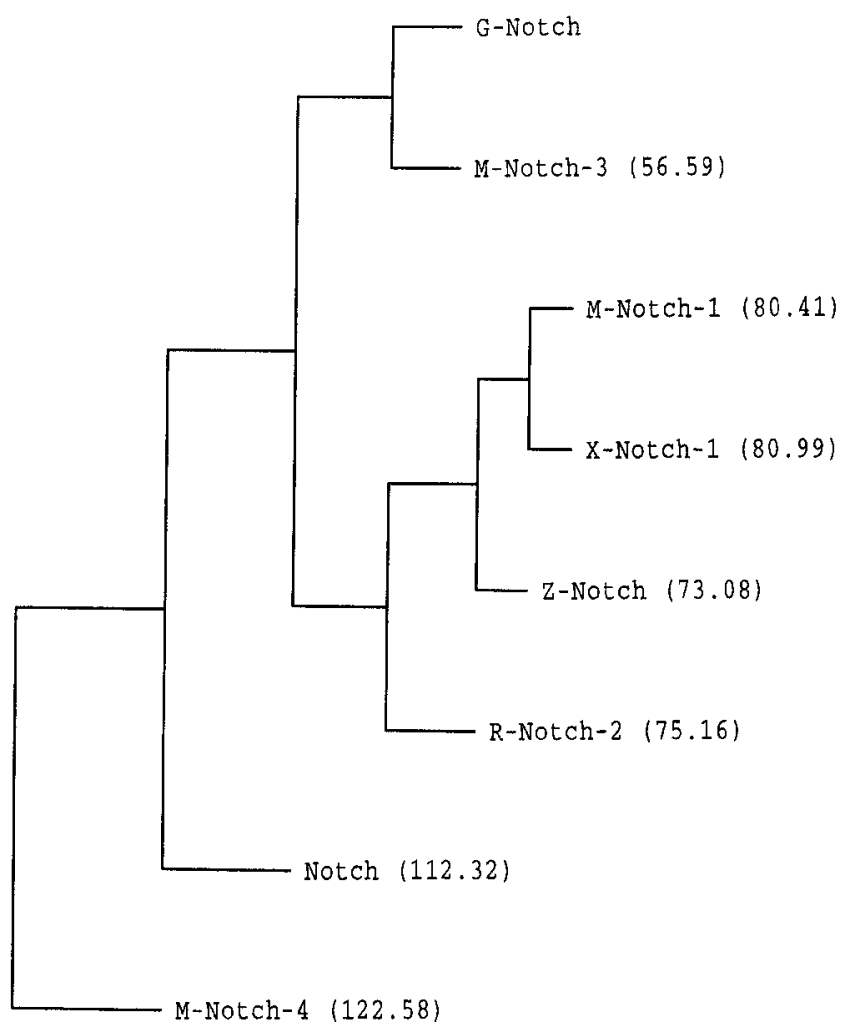

Fig. 4. Relatedness of representative Notch proteins to G-Notch and to each other. The region of most contiguous homology to G-Notch was identified for each homologue using BESTFIT and aligned using PILEUP. The DISTANCES program was used to generate a protein distance matrix from the aligned sequences, which was input to GROWTREE in order to generate a phylogeny tree. Numbers in parentheses next to sequence names indicate the relatedness of each Notch sequence to G-Notch, in terms of estimated number of amino acid substitutions per 100 amino acids, as calculated by DISTANCES. M-Notch-1, mouse Notch-1 [del Amo et al., 1993]; R-Notch-2, rat Notch-2 [Weinmaster et al., 1992]; M-N otch-4, mouse Notch-4 [Uyttendaele et al., 1996]; Notch, Drosophila Notch [Artavanis-Tsakonas et al., 1983]; X-Notch-1, Xenopus N otch-1 [Coffman et al., 1990].

from the 26th EGFL repeat to the PEST region, encompassing well-conserved lin/Notch, transmembrane, ANK, and BNLS regions (Fig. $3 A, B$ ). The opa repeats found in the intracellular region of Drosophila Notch, on the other hand, are vestigial in G-Notch, as is true for other vertebrate N otch homologues.

Four classes of Notch proteins have been described in mammals. Notch-1 and Notch-2 display minor differences in amino acid sequence [Weinmaster et al., 1991, 1992]. Notch-3 and Notch-4 lack the full complement of EGFL repeats, with Notch-3 having 34 and Notch-4 having 29 [Lardelli et al., 1994; Uyttendaele et al., 1996]. Pairwise sequence comparisons and calculation of phylogenetic distances between representative N otch proteins (Fig. 4) suggest that G-Notch represents a member of the Notch-3 class. This assignment is necessarily provisional, since G-N otch sequence data do not 

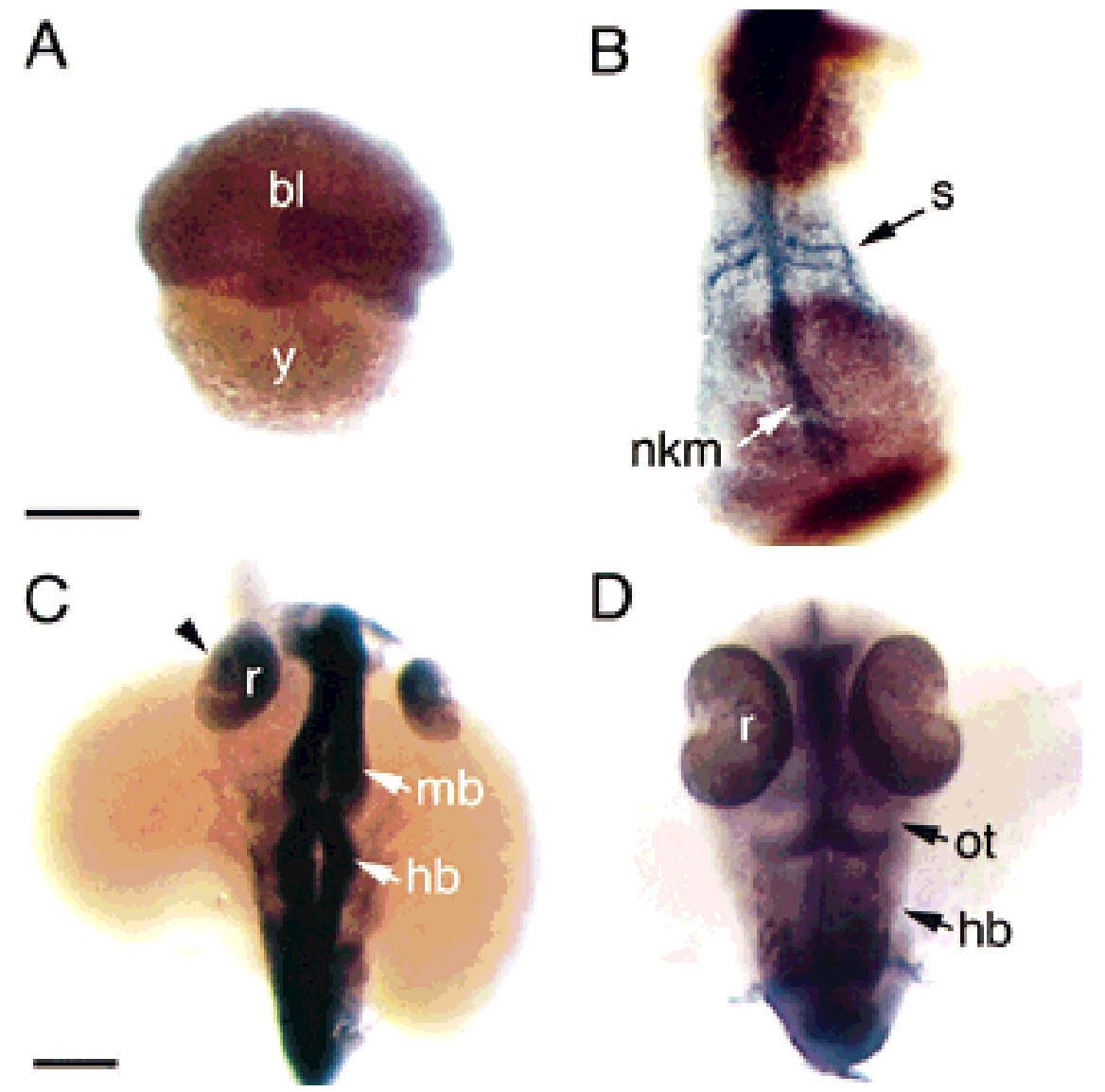

Fig. 5. Developmental expression pattern of G-Notch visualized in whole embryos by in situ hybridization; the reaction product is blue/violet. Anterior is up in all panels. A: Stage 12 (beginning of gastrulation); G-Notch is expressed throughout the blastoderm (bl), which has extended across approximately $50 \%$ of the yolk (y). B: Stage 15-16 (embryonic shield, 2-3 somites); the shield (neural plate equivalent) has been dissected away from the yolk. G-Notchexpressing somitic furrows (s) and the medial element of the presumptive neural keel $(\mathrm{nkm})$ are evident; the lateral neural keel elements are too faint to see in this preparation. C: Stage 19 (optic cup and lens

formation); swellings and constrictions of the neural tube mark future midbrain (mb) and hindbrain (hb) divisions. G-Notch expression is nearly uniform in intensity along the length of the neural tube, in the retina $(r)$ and the lens placode (arrowhead). D: Stage 23 (beating heart); pigmentation obscures the relatively meager G-N otch expression remaining in the retina ( $r$ ), although expression in midline (i.e., ventricular) regions of the brain remains distinct. Note expression also in the caudal margin of the optic tectum (ot), a region that contributes heavily to the adult tectal germinal zone. Bars $=100 \mu \mathrm{m}(\mathrm{A})$ and 200 $\mu \mathrm{m}$ (C, also applies to B, D).

Fig. 6. Developmental expression of G-Notch visualized in sectioned embryos. A-D: Sections from embryos that were cryosectioned prior to in situ hybridization. E-G: From embryos raised in $0.003 \%$ 1-phenyl-2-thiourea to retard pigmentation, then processed whole for in situ hybridization, embedded in methacrylate and sectioned at 3 $\mu \mathrm{m}$. A: Stage 22 (body pigmentation); a slightly oblique parasagittal section, showing G-Notch expression along the extent of the neural tube (nt; hindbrain, hb; midbrain, $\mathrm{mb}$ ), in the otic capsule (oc), retina ( $\mathrm{r}$ ), and lens (I), and presumptive gill arches (ga). B: Enlargement of the area of the trunk bracketed in A, showing that G-N otch expression is restricted to neural tissue; epidermis (ep), notochord (no) and myomeres (my) are negative. C: Transverse section through a stage 22 hindbrain (hb) showing G-Notch expression restricted to ventricular regions. The roof of the fourth ventricle, (v4) has collapsed. Note also expression in the otic capsular (oc) epithelium. D: Stage 22 eye, showing absence of G-N otch expression in the earliest differentiating regions, i.e., around the choroid fissure ( $\mathrm{cf}$ ) and cellular layers nearest the vitreal cavity or lumen (lu). E: Stage 25 (hatching); G-Notch is expressed in thin, presumptive ependymal layers (arrowhead) of the brain, e.g., the surfaces of the everted telencephal on (te). The retinal germinal zones (gz) express G-N otch, but expression has disappeared from the differentiating, laminated retina $(r)$ and the lens (I). F : Stage 25 (hatching); the ventricular lining of the hypothalamic ventricles (arrowhead) of the diencephal on (di) and the mesenchyme of the gill arches (ga) express G-Notch. G: Stage 25 (hatching); Expression persists in the ventricular lining (arrowheads) of the midbrain (mb) and hindbrain (hb), in the otic capsule (oc) and mesenchyme of the head and pectoral fins (pf). Bars $=100 \mu \mathrm{m}(\mathrm{A})$ and $100 \mu \mathrm{m}(\mathrm{E}$, also applies to $\mathrm{F}$ and $\mathrm{G})$. 

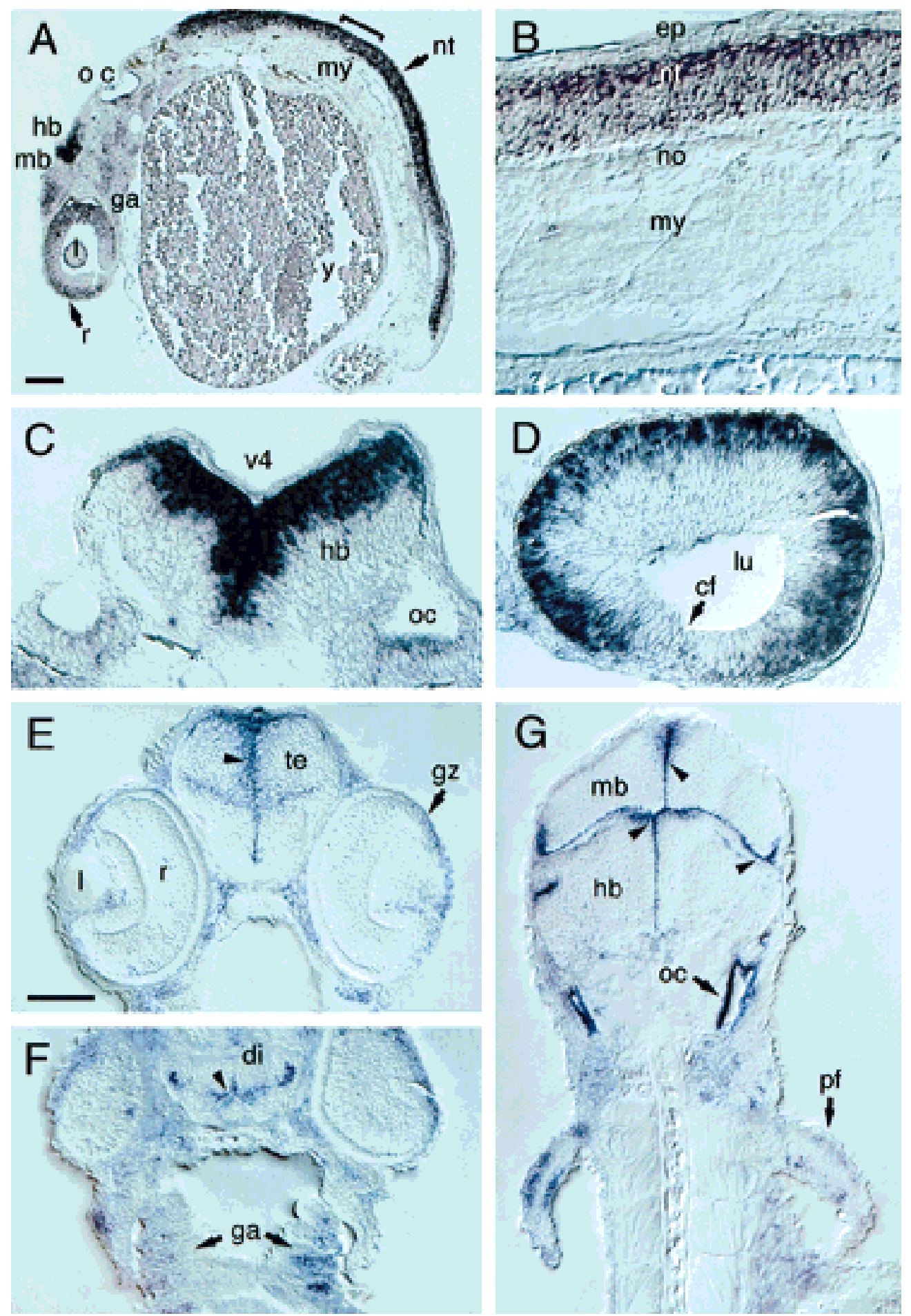

Fig. 6. 
yet extend into the extracellular region (EGFL repeats 2-21) where the two EGFL repeats that are absent in Notch-3 lie [Lardelli et al., 1994].

\section{Embryonic Expression of G-Notch: In Situ Hybridization}

At the beginning of gastrulation (50\% epiboly, stage 12) G-Notch is expressed throughout the goldfish blastoderm (Fig. 5A). Expression is seen in both the epiblast (presumptive ectoderm) and hypoblast (presumptive endo-mesoderm) germ layers (data not shown). By early neurulation (stages 15-16), G-N otch expression is localized to a midline stripe (Fig. 5B) and more faintly in twolateral stripes. Based on descriptions of zebrafish embryol ogy [Schmitz et al., 1993], these probably repre sent the tripartite elements of the presumptive neural keel. Mesodermal expression is concentrated in the posterior boundaries of the first somites (Fig. 5B], which as in zebrafish develop concurrently with the neural keel [Schmitz et al., 1993].

As subdivisions of the brain become morphologically distinct, G-Notch is expressed robustly in neuroepithelia of all CNS structures including the optic cup (Fig. 5C, stage 19). Lens and auditory (otic) placodes also express G-Notch, although the epidermis does not (Fig. 5C). Although somitic expression is still visible at stage 19 (not shown), when body pigmentation begins (stage 22), differentiated myomeres have ceased expressing G-N otch (Fig. 6A,B). By this stage, the neuroepithelium has become a multilayered structure, and within it, G-Notch expression persists in the periventricular mitotic zone but has ceased in more lateral zones containing migrating and differentiating cells (Fig. 6C) and is not expressed in floor plate (data not shown).

At stage 22, retinal cell differentiation has begun at the choroid fissure and in the future inner cell layers throughout the retina [Sharma and Ungar, 1980] (P.A. Raymond, unpublished observations), and retinal G-N otch is downregulated in these regions (Fig. 6D). As early as the beating-heart stage (stage 23), G-Notch expression in the optic tectum of the midbrain is restricted to its midline and caudal margins (Fig. 5D), which persist as germinal zones in the adult tectum [Kirsche, 1960; Kirsche and Kirsche, 1961; Raymond and Easter, 1983]. In older embryos, expression in the CNS is primarily seen in the presumptive germinal zone (GZ) in the retina, and the presumptive ventricular lining (ependyma) of the brain (Fig. 6E,G). Mesenchymal and neural crest cell-derived G-Notch expression is also seen in various regions, including the head, gill arches, and fin buds of late embryos (Fig. 6E-G). By 10 days post-hatching, G-Notch expression persists only in a thin periventricular zone in the brain and in the spinal cord (data not shown).

\section{G-Notch Expression in the Adult Goldfish CNS}

RNase protection assays of total RNA from adult goldfish tissues indicated that G-Notch is expressed in

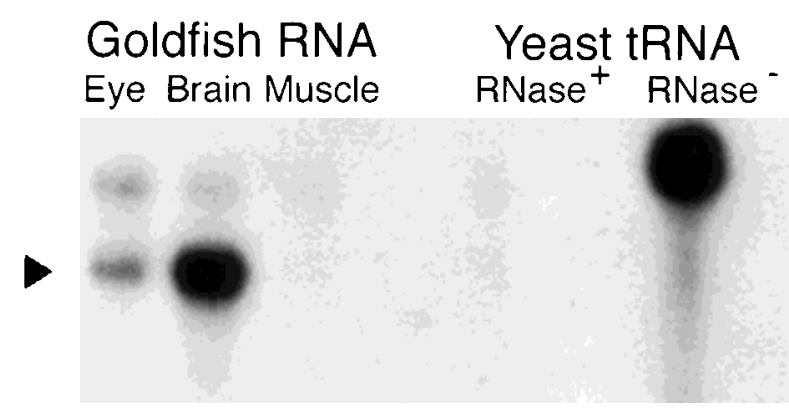

Fig. 7. RNase protection assay showing the presence of G-Notch transcripts (arrowhead) in the brain and eye but not flank muscle of adult goldfish. The larger fragment present in all lanes is a contaminating template cDNA. Yeast tRNA was included as a control.

adult brain and eyes, but not in adult skeletal muscle (Fig. 7). We subsequently performed in situ hybridization studies to localize this expression.

Several sites of G-N otch expression were revealed by hybridization to parasagittal sections of adult brain. The ependymal lining of the forebrain in teleosts is in an atypical location: it underlies the pial, or outer, surface [Richter and Kranz, 1970b]. This unusual arrangement is due to an eversion of the telencephalic ventricle that is characteristic of teleost brain morphogenesis [Nieuwenhuys and Meek, 1990]. The everted ependyma of the forebrain expresses G-Notch, whereas expression ceases abruptly at the junction with the pial surface of the non-everted midbrain (Fig. 8B). However, G-N otch expression continues in the ependymal lining of the tectal (Fig. 8A,B) and hypothalamic ventricles (not shown). In the tectum, G-Notch is also expressed deeper in the ventricular wall, in the stratum periventricular (Fig. 8C,D). This layer corresponds to the "periependymal" zone wherein a persistent population of radial glia resides [Stevenson and Yoon, 1981, 1982].

J ust as the retinal GZ forms the rim of the hemispheric retina, so the tectal GZ is located in the rim of each hemispheric tectal lobe. In the GZ of the tectum, as in the retinal $\mathrm{GZ}$, the laminar cytoarchitecture collapses into a pseudostratified, primitive neuroepithelium of proliferating cells [Raymond and Easter, 1983]. In parasagittal sections the tectal GZ appears as a cluster of cells at the caudal junction of the tectum and the cerebellum; these cells strongly express G-Notch (Fig. 8E ,F ). Thetegmental GZ, which may be a continuation of the tectal GZ [Kirsche, 1960; Raymond and Easter, 1983], al so expresses G-Notch (Fig. 8E ,F ).

In the retina, G-Notch expression was strongest in the $G Z$, where the densest population of retinal neuronal progenitors resides (Fig. 9A). Some recently-generated cells in the inner retinal layers near the $G Z$ also express G-Notch. Weakly expressing cells were also occasionally found in the inner nuclear (INL) and ganglion cell $(G C L)$ layers, but not in the outer nuclear layer (ONL), where rod precursors and photoreceptor somata reside (Fig. 9A, B). The precise identities of cells expressing 

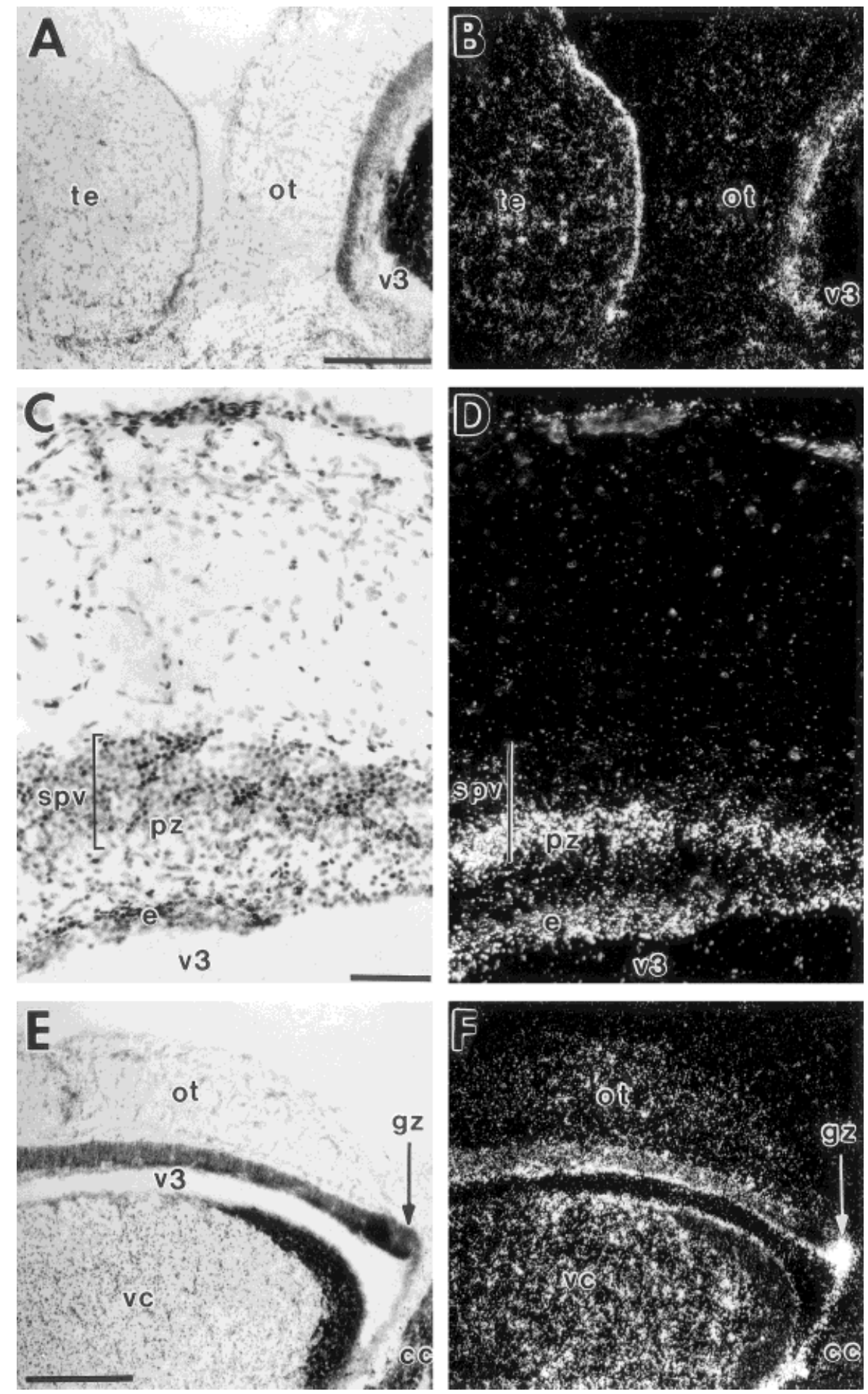

Fig. 8. Expression of G-Notch in adult goldfish brain correlates with proliferative regions. Anterior is left, dorsal is up. Brightfield $(A, C, E)$ and darkfield $(B, D, F)$ views of the same sections after radioactive in situ hybridization to G-Notch probes; the signal appears as white grains in darkfield illumination. A,B: Parasagittal section containing the junction of the forebrain (telencephalon, te) and the optic tectum of the midbrain (ot). The ependymal layer of the evaginated forebrain expresses G-Notch, as does the corresponding ventricular layer of the optic tectum (ot), which encloses the third

ventricle (v3). C,D: Parasagittal section of the tectum, showing G-Notch expression mainly confined to the ependymal lining (e) of v3 and to the ventricular side (periependymal zone, pz) of the adjacent cellular layer, the stratum periventriculare (sp). E,F: Parasagittal view of the caudal end of the tectum, where the tectal germinal zone (gz) strongly expresses G-Notch. The tegmental germinal zone, which also expresses G-Notch, is just visible in the lower right part of the panel, where the valvular cerebellum (vc) and caudal cerebellum (cc) join. Bars $=100 \mu \mathrm{m}(\mathrm{A}$ and $\mathrm{E})$ and $50 \mu \mathrm{m}(\mathrm{C})$. 
G-Notch in the adult retina were not determined in this study.

\section{G-Notch Expression in Injured and Regenerating Retinas}

G-Notch expression was investigated in retinas subjected to two types of focal injury, retinal puncture and laser lesion, both of which stimulate proliferation of intrinsic neuronal progenitor populations [Sullivan and Raymond, 1991; Braisted et al., 1994]. With the parameters used, the laser lesions specifically ablate photoreceptors in the target region, while retinal puncture causes non-specific damage. In previous studies we have characterized the regeneration of both rods and cones in response to laser lesions [Braisted et al ., 1994]. In the present study we found that in both paradigms G-Notch expression increased locally within a few days in the retinal regions surrounding the lesioned area (Fig. 9B,D). As in uninjured retinas, BrdU labeling showed that only a subset of G-Notch expressing cells are mitotically active (Fig. 9C,D). Labeling with GFAP antibody, which marks Müller glia [Wagner and Raymond, 1991; Erickson et al., 1992], revealed that many G-Notch-expressing foci of cells are associated with glial processes, but it does not appear that all G-Notchexpressing cells also express GFAP (Fig. 9E ).

By 5 days after the laser lesion, novel G-Notch expression appears in the outer nuclear layer (ONL) of the injured retina (Fig. 9C,E). These are proliferating cells which within the next few weeks will give rise to regenerated cone and rod photoreceptors [Braisted et al., 1994]. The origin of these clusters of cells, whether from rod precursors al ready located in the ONL or from neurogenic stem cells in the inner nuclear layer (INL) has not been establi shed. I t has been shown that Müller cell nuclei, normally found only in the INL, migrateinto the ONL following ablation of photoreceptors [Braisted et al., 1994]. Whatever their origin, it is clear that these cells which are responsibl e for regenerating photoreceptors have abundant G-N otch expression, similar to the dividing and differentiating neuroepithelial cells in the GZ at the growing margin. Beyond theselocal regenerative responses, the level of G-Notch expression, especially in the INL and in the GZ, increases throughout the retina. Thus, injury to the retina alters both the level and the location of G-Notch expression.

\section{DISCUSSION}

The sequence data presented here strongly suggest that G-N otch represents a member of the Notch family. G-Notch encodes a peptide containing all of the motifs present in a canonical Notch protein, and also their spacing. This high degree of structural conservation implies important functions for the various motifs, and indeed the conserved EGFL, ANK, and C-terminal regions have been found necessary for proper functioning of the Notch signaling pathway in fruit flies, amphibians, and mammals [Rebay et al., 1993; Coffman et al., 1993; J arriault et al., 1995].

The question of to which N otch class G-N otch belongs is probably not trivial, since it has been shown in mice that neither the expression patterns nor the functions of Notch orthologues are redundant [Swiatek et al., 1994; Williams et al., 1995]. G-Notch most likely encodes a member of the Notch-3 class previously represented solely by a murine cDNA [Lardelli et al., 1994]. Although specific functions of the Notch orthologues remain uncertain, mutations in the human Notch-3 gene recently have been identified in a familial syndrome known as CADASIL (cerebral autosomal dominant arteriopathy with subcortical infarcts and leukoencephalopathy) causing dementia and stroke with adult onset [J outel et al., 1996]. Sequence analysis of N otch-1 and Notch-2 proteins [Maine et al., 1995] has shown that Notch paralogues (e.g., M-Notch-1 vs. X-Notch-1)
Fig. 9. Expression of G-Notch in the adult retina is upregulated after injury and during photoreceptor regeneration. In situ hybridization of retinal cryosections; the colorimetric reaction product has a purple/violet hue. A: G-Notch is expressed in the germinal zone (gz) at the margin of the retina and in the adjacent (immature) postmitotic cells. The differentiated retina is laminated, with photoreceptor nuclei in the outer nuclear layer (on), and various retinal neurons and glial cells in the differentiated inner nuclear (in) and ganglion cell (gc) layers. At the back of the neural retina is the retinal pigmented epithelium (rpe), which is filled with dark brown melanin. B: At 15 days following wounding (retinal punctures), G-Notch expression is upregulated in the germinal zone (gz) and inner nuclear (in) layer. The refractile profiles between the outer nuclear (on) layer and the retinal pigmented epithel ium are photoreceptor processes (pr). A circumferential blood vessel (bv) surrounds the retina adjacent to the gz. C: In the region of a retinal puncture (arrow), proliferating cells (light pink) have incorporated bromodeoxyuridine (BrdU), which was visualized by immunofluorescence (arrowheads). The proliferating cells are found in all retinal layers. G-Notch expression is upregulated in the inner nuclear (in) and ganglion cell (gc) layers (although this double exposure of immunofluorescence and brightfield illumination makes the in situ signal difficult to appreciate at this low magnification). D: In the same section as in panel $\mathrm{C}$, but at the retinal margin (which is located several hundred micrometers or more from the site of the nearest wound), proliferating neuroepithelial cells in the germinal zone (gz) and rod precursors in the outer nuclear (on) layer (arrowhead) are mitotically stimulated, as are glia (in the gc layer, arrowhead), a few cells in the inner nuclear (in) layer, and vascular cells (in the circumferential blood vessel, bv). E: Retina at 5 days following a laser lesion that destroys photoreceptors. The boundaries of the lesion are indicated by the large asterisks in the outer nuclear (on) layer; note the absence of refractile photoreceptor processes within the lesion. Note also the disruption in the rpe associated with the lesion, and the infiltration of inflammatory cells (if). The small asterisk in the ganglion cell (gc) layer indicates a displaced, pigmented cell. This section was processed for in situ hybridzation, followed by immunofluorescence using anti-GFAP, which is localized to radial Müller glial cells, whose processes span the retinal thickness (arrows). Note the strong G-N otch expression in the outer nuclear layer (shown at higher magnification in the inset). Bars $=50 \mu \mathrm{m}(\mathrm{A}) ; 50 \mu \mathrm{m}$ (B, also applies to C and D); $25 \mu \mathrm{m}(\mathrm{E})$. 

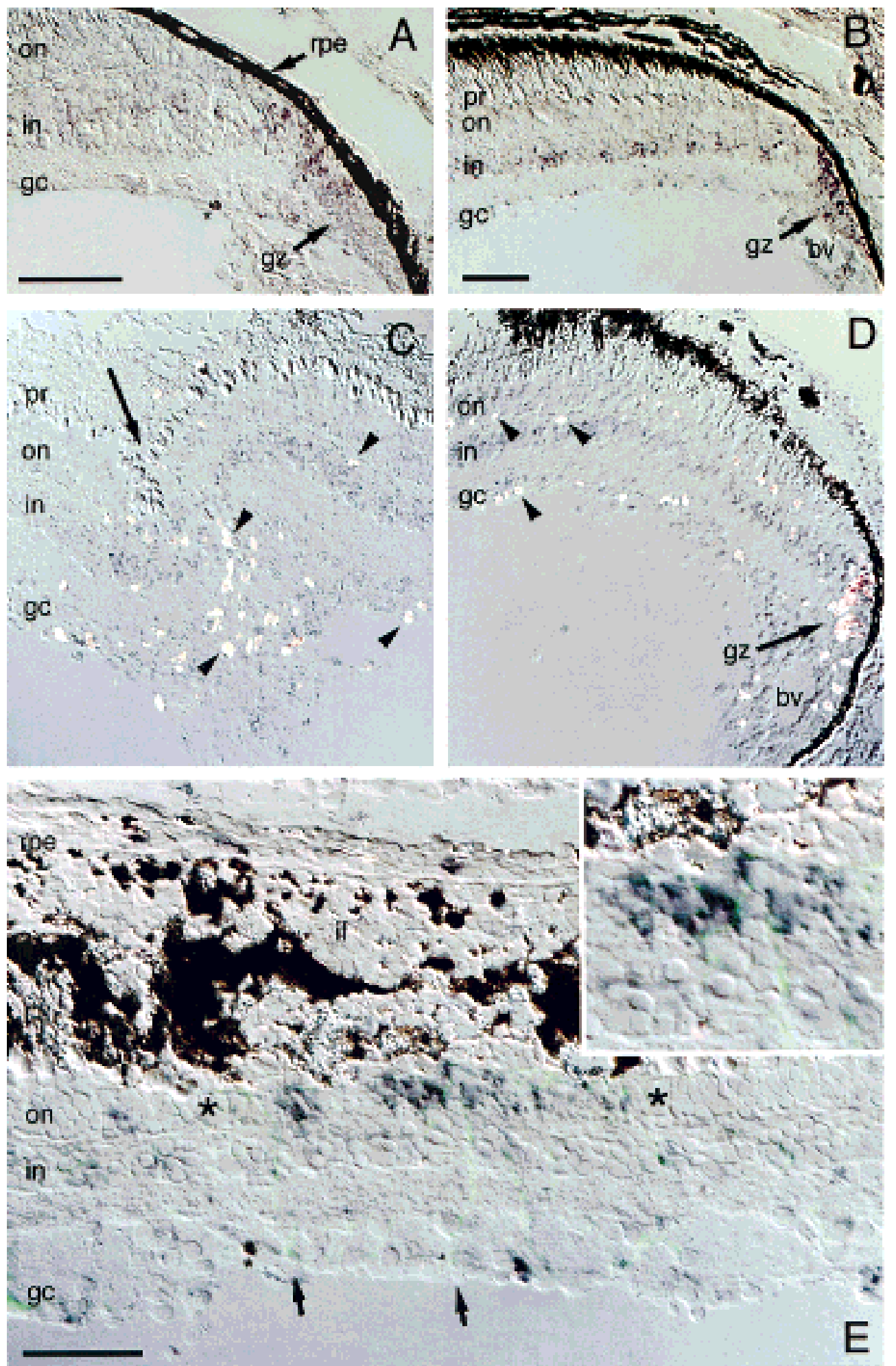

Fig. 9. 
are less divergent than Notch orthologues (e.g., M-N otch-1 vs. M-Notch-2). Thus we would predict that a goldfish Notch-3 would be more homologous to a mammalian Notch-3 than to a member of a different Notch class in goldfish or a closely related species. In agreement with this inference, G-N otch is more homologous to M-Notch-3 than to zebrafish Z-Notch, which our sequence analysis shows is in the Notch-1 class. As only a single Notch gene is present in Drosophila, it has been previously proposed that the evolution of Notch paralogues occurred between the divergence of arthropods and amphi bians from the mammalian lineage [Lardelli and Lendahl, 1993; Lardelli et al., 1994]; our analysis further localizes this event in time to before the evolution of tel eost fishes.

Our expression data al so support the identification of G-Notch as a Notch gene, particularly its expression in proliferative neuroepithelia. For example, expression in the proliferating ventricular zone of the embryonic murine neural tube is characteristic of Notch-1, -2 , and -3 [Lardelli et al., 1994; Higuchi et al., 1995]. However, assignment of G-Notch to a specific N otch class based on expression data is complicated by the paucity of such data for lower vertebrates, where only Notch-1 expression patterns have been documented [Coffman et al., 1990; Bierkamp and Campos-Ortega, 1993], and by inconsistencies in descriptions of rodent Notch orthologue expression patterns [Weinmaster et al., 1992; Lardelli et al., 1994; Higuchi et al., 1995; Williams et al., 1995]. G-Notch expression accords with that of M-Notch-3 in that both (1) occur in the ectoderm and mesoderm of gastrulating embryos, (2) are absent in notochord and floor plate, (3) are strong in the embryonic periventricular neuroepithelium and the otic vesicles, and (4) occur in adult brain [Lardelli et al., 1994; Williams et al., 1995; Lindsell et al., 1995]. However, expression patterns of M-Notch-3 and G-Notch are not completely analogous. For example, M-Notch-3 expression was detected in embryonic rodent epidermis and adult skeletal muscle, and not in the mostly undifferentiated E10.5 retina [Lardelli et al., 1994; Williams et al., 1995]. These discrepancies may reflect differences in probe sensitivities, species-specific adaptations of Notch-3 function, or alternatively, G-Notch might represent a novel class of Notch. The existence of a zebrafish Notch-1 and of multiple Notch orthologues in mammal ian species suggests that additional gol dfish orthologues of G-Notch await discovery.

What role(s) might G-Notch play in its various sites of expression? Although Notch expression often correlates with cellular proliferation, it has been shown that the two events can be uncoupled without altering Notch expression patterns [Coffman et al., 1993]. Furthermore, in the Xenopus retina, X-Notch- 1 expression overlaps only partially with the mitotic germinal zone [Dorsky et al., 1995], as we have reported here in gol dfish for G-Notch, indicating that no simple relationship exists between mitosis and Notch expression.
Notch has more compellingly been implicated in processes of commitment and early differentiation of cells, which are proximal events to terminal mitosis. The accumulated evidence suggests that Notch is involved in cell fate decisions not as a specifier of particular cell fates, but as an antagonist to differentiation in a variety of developmental contexts, among them neurogenesis [Fortini et al., 1993; Chitnis et al., 1995; Chitnis and Kintner, 1996; Nyeet al., 1994] and myogenesis [Conlon et al., 1995; Nye et al., 1994; Kopan et al., 1994]. Alterations of Notch activity in the Drosophila CNS and ommatidia [Cagan and Ready, 1989; Rebay et al., 1993], in the retina of chick [Austin et al., 1995], and in the Xenopus neural plate [Coffman et al., 1993; Chitnis et al., 1995] produce shifts in numbers of the specific cell types normally produced during the period of disruption. These shifts are characteristic of a factor that inhibits differentiation, in that reduction in activity leads to overproduction of a cell type, while increased activity causes its underproduction. This function is particularly vital wherever sequential fatechoices are made, as in the developing CNS. In the embryonic goldfish retina we observed a central-to-peripheral and vitreal-to-lumenal gradient of G-Notch expression that approximately parallels the differentiation of goldfish retinal cells; for example, the ganglion cell layer in the central retina differentiates first [Sharma and Ungar, 1980], concurrent with downregulation of G-N otch expression in the inner retina. Similarly the laminar organization of the neural tube develops in a peripheralto-ventricular gradient, complementing the pattern of G-Notch expression. Thus, the pattern of G-Notch expression is consistent with a role for G-Notch in the maintenance of the undifferentiated state in these embryonic tissues.

G-Notch expression patterns in adult goldfish brain and retina argue for a similar role for this gene in postembryonic CNS growth and regeneration. In the brain G-Notch is expressed in the tectal germinal, ependymal, and periependymal zones, all of which contain proliferative cell populations. The goldfish tectal GZ consists of proliferative cells with neuroepithelial morphology, whose progeny, as determined by ${ }^{3} \mathrm{H}$-thymidine uptake studies, are both neuronal and glial [Raymond and Easter, 1983]. The tectal GZ is al so essential for tectal regeneration; cell proliferation in deep tectal layers (i.e., the ependyma and periependyma) alone is insufficient to restore tectal morphol ogy following brain lesions [Kirsche, 1960; Kirsche and Kirsche, 1961; Richter, 1968; Richter and Kranz, 1977; Stevenson and Yoon, 1980]. Ependymal cells and radial glial cells of the periependyma al so have mitotic potential [Stevenson and Yoon, 1981, 1982; Raymond and Easter, 1983]; a role for G-N otch in the maintenance of relatively undifferentiated pools of cells in the GZ and periventricular glial layers of the brain is therefore plausible. Expression of G-Notch in both ependymal and periependymal glial progenitor zones might even 
reflect an underlying relationship between the two cell types, since explants of ependymal cells from proliferative regions of adult songbird forebrain produce radial glia [Goldman et al., 1994].

In the adult retina, G-Notch expression in the GZ may be functionally analogous to that seen in the tectal GZ and in the embryonic retinal neuroepithelium, since these are all sites of neurogenesis. Similarly, if the G-N otch + cells in the differentiated INL correspond to the normally quiescent stem cell-like populations reported in the INLs of both trout and goldfish [reviewed in Raymond and Hitchcock, 1997], G-N otch expression might act to keep them in an undifferentiated state. Since this function of Notch requires its interaction with Delta or Delta-like ligands produced by adjacent cells [Gu et al., 1995; Chitnis et al., 1995; Myat et al., 1996], it would be illuminating to obtain teleost Delta genes and examine their expression patterns in adult retina and in brain regions that express G-Notch. Another vertebrate Notch ligand recently identified is J agged, a transmembrane protein with structural similarities to the Drosophila Notch ligand Serrate [Lindsell et al., 1995]. In rat embryos, J agged is expressed in bilaterally symmetric, longitudinal stripes in the ventricular zone of the spinal cord, overlapping the expression domains of rat Notch-1, -2 , and -3 . Since J agged is also expressed in many other tissues during embryonic development in the rat, including the dorsal root ganglia, eye, ear, kidney, pancreas, limb bud, and skin [Lindsell et al., 1995], it would also be instructive to identify a teleost J agged homologue and compare the expression patterns to those of G-N otch.

We also observed G-Notch expression in a subset of cells in the adult ganglion cell layer (GCL). Although the identities of these cells were not determined, M-N otch-1 expression has been reported in the INL and GCL of adult rat retina, which apparently lacks neural progenitor cell populations [Ahmad et al., 1995]. The function of Notch in this context remains to be defined, but since both of these retinal layers contain glial cells, which are capable of proliferation, it is plausible that Notch is expressed in these cells.

Proliferation of neuronal progenitor populations is a common reaction to retinal injury in goldfish in a variety of lesion paradigms, chemical as well as mechanical [reviewed in Raymond and Hitchcock, 1997]. In this study we observed widespread upregulation of G-Notch expression in injured retinas along with novel expression in the photoreceptor cell layer, associated with regeneration of photoreceptor cells. In surgically lesioned goldfish retinas, it has similarly been shown that regenerating cells upregulate expression of other developmentally regulated genes: pax6 and vsx1, both members of the paired-class homeobox family of transcription factors [Hitchcock et al., 1996; Levine et al., 1994]. Disrupting the integrity of the retina and the pigmented epithel ium is likely to rel ease growth factors normally sequestered by the extracellular matrix [Sulli- van and Raymond, 1991; Raymond et al., 1992], which can stimulate proliferation [Gao and Hollyfield, 1992; Raymond et al., 1992; Lewis et al., 1992] and may alter expression of these regulatory genes. The upregulation of G-N otch expression, like the stimulation of mitotic activity, was not confined to the region at and immediately surrounding the retinal wound. Presumably most of the superfluous cells that proliferate outside the injured region either fail to survive or do not differentiate, although this has not been verified. A possible role of increased G-Notch expression in these undamaged regions would be to insure that differentiated cells are not overproduced in response to liberated growth factors.

We also noted that G-Notch expression in the INL and ONL was contiguous with GFAP immunoreactivity, which is also upregulated in injured retinas [Erickson et al., 1992; Braisted et al., 1994]. Both Müller glia, which express GFAP, and the putative stem cell in the I NL prol iferate in response to injury [Lewis et al., 1994; Wagner and Raymond, 1991; Braisted et al., 1994]. An alternative role of G-Notch expressed at the junction of glia and neural progenitors could be a mechanical function. There is evidence from Drosophila that the ligand-binding properties of Notch-like proteins could serve as guidance cues for migrating cells or growing axons [Giniger et al., 1993; Menne and Klambt, 1994]. Outward migration of proliferating INL cells along Müller glial processes occurs in goldfish larvae before the appearance of rod precursors in the ONL [Raymond and Rivlin, 1987], and Sharma [1975] has described a similar process of neuronal migration along radial fibers in the developing optic tectum of the trout. The retinal Müller glia and the periependymal radial glia of goldfish may represent a scaffold-like component of a cell-migratory mechanism for constructing new tissue. If so, G-Notch could play roles that are both instructive (guidance on radial glia) and prohibitive (suppression of differentiation) in devel oping and regenerating CNS.

\section{ACKNOWLEDGMENTS}

We thank Dr. Michal Schwartz for the FGP2 antibody, Dr. William Harris for the X-N otch-1 CDNA clone, and Dr. Daniel Goldman for the gift of a cDNA library. We are also grateful to Dr. Goldman and Dr. Virginia Heiber for their generous help with radiolabeled in situ hybridization and cloning procedures. Mr. David Wu and Dr. Todd Schneiderman provided the goldfish with laser lesi oned retinas. Mr.J ames Beal assisted with the digital image printing. We thank Dr. Sally Moody for helpful suggestions on the manuscript. This work was supported by NIH EY04318 (P.A.R.). P.A.R. has published previously as PR J ohns.

\section{REFERENCES}

Ahmad I, Zagouras P, Artavanis-Tsakonas S (1995): I nvolvement of Notch-1 in mammalian neurogenesis: Association of N otch-1 activity 
with both immature and terminally differentiated cells. Mech Dev 53:73-85.

Artavanis-Tsakonas S, Muskavitch MA, Yedvobnick B (1983): Molecular cloning of Notch, a locus affecting neurogenesis in Drosophila melanogaster. Proc Natl Acad Sci USA 80:1977-1981.

Artavanis-Tsakonas S, Matsuno K, Fortini ME (1995): Notch signaling. Science 268:225-232.

Austin CP, Feldman DE, I da J AJ , Cepko CL (1995): Vertebrate retinal ganglion cells are selected from competent progenitors by the action of Notch. Development 121:3637-3650.

Barthel LK, Raymond PA (1993): Subcellular localization of alphatubulin and opsin mRNA in the goldfish retina using digoxigeninlabeled CRNA probes detected by alkaline phosphatase and HRP histochemistry. J Neurosci Methods 50:145-152.

Bierkamp C, Campos-Ortega J A (1993): A zebrafish homologue of the Drosophila neurogenic gene $\mathrm{N}$ otch and its pattern of transcription during early embryogenesis. Mech Dev 43:87-100.

Braisted J E, Essman TF, Raymond PA (1994): Sel ective regeneration of photoreceptors in gol dfish retina. Development 120:2409-2419.

Cagan RL, Ready DF (1989): Notch is required for successive cell decisions in the developing Drosophila retina. Genes Dev 3:10991112.

Chitnis A, Kintner C (1996): Sensitivity of proneural genes to lateral inhibition affects the pattern of primary neurons in Xenopus embryos. Development 122:2295-2301.

Chitnis A, Henrique D, Lewis J , Ish-Horowicz D, Kintner C (1995): Primary neurogenesis in Xenopus embryos regulated by a homologue of the Drosophila neurogenic gene Del ta. Nature 375:761-766.

Chomczynski P, Mackey K (1994): One-hour downward capillary blotting of RNA at neutral pH. Anal Biochem 221:303-305.

Coffman C, Harris W, Kintner C (1990): Xotch, the Xenopus homol og of Drosophila Notch. Science 249:1438-1441.

Coffman CR, Skoglund P, Harris WA, Kintner CR (1993): Expression of an extracellular deletion of Xotch diverts cell fate in Xenopus embryos. Cell 73:659-671.

Conlon RA, Reaume AG, Rossant J (1995): Notch1 is required for the coordinate segmentation of somites. Development 121:1533- 1545.

Davis CG (1990): The many faces of epidermal growth factor repeats. New Biol 2:410-419.

del Amo FF, Gendron-Maguire M, Swiatek PJ , J enkins NA, Copeland NG, Gridley T (1993): Cloning, analysis, and chromosomal localization of Notch-1, a mouse homolog of Drosophila Notch. Genomics 15:259-264.

Dingwall C, Laskey RA (1991): Nuclear targeting sequences-A consensus? Trends Biochem Sci 16:478-481.

Dorsky RI, Rapaport DH, Harris WA (1995): Xotch inhibits cell differentiation in the Xenopus retina. Neuron 14:487-496.

Erickson PA, Feinstein SC, Lewis GP, Fisher SK (1992): Glial fibrillary acidic protein and its mRNA: Ultrastructural detection and determination of changes after CNS injury. J Struct Biol 108:148-161.

Fortini ME, Rebay I, Caron LA, Artavanis-Tsakonas S (1993): An activated Notch receptor blocks cell-fate commitment in the developing Drosophila eye. Nature 365:555-557.

Gao H, Hollyfield J G (1992): Basic fibroblast growth factor (bFGF) immunolocalization in the rodent outer retina demonstrated with an anti-rodent bFGF antibody. Brain Res 585:355-360.

Giniger E, J an LY, J an YN (1993): Specifying the path of the intersegmental nerve of the Drosophila embryo: A role for Delta and Notch. Development 117:431-440.

Goldman SA, Lemmon V, Chin SS-M (1994): Migration of newly generated neurons upon ependymally derived radial guide cells in explant cultures of the adult songbird forebrain. Glia 8:150-160.

Gu Y, Hukriede NA, Fleming RJ (1995): Serrate expression can functionally replace $D$ el ta activity during neuroblast segregation in the Drosophila embryo. Development 121:855-865.

Hieber V, Agranoff BW, Goldman D (1992): Target-dependent regulation of retinal nicotinic acetylcholine receptor and tubulin RNAs during optic nerve regeneration in goldfish. J Neurochem 58:10091015.

Higuchi M, Kiyama H, Hayakawa T, Hamada Y, Tsujimoto Y (1995):
Differential expression of Notch1 and Notch2 in developing and adult mouse brain. Brain Res Mol Brain Res 29:263-272.

Hitchcock PF, Raymond PA (1992): Retinal regeneration. Trends Neurosci 15:103-108.

Hitchcock PF, Lindsey Myhr KJ , Easter SS, Mangione-Smith R, J ones DD (1992): Local regeneration in the retina of the goldfish. J Neurobiol 23:187-203.

Hitchcock PF, Macdonald RE, VanDeRyt JT, Wilson SW (1996): Antibodies against pax6 immunostain amacrine and ganglion cells and neuronal progenitors, but not rod precursors, in the normal and regenerating retina of the goldfish. J Neurobiol 29:399-413.

J arriault S, Brou C, Logeat F, Schroeter EH, Kopan R, I srael A (1995): Signalling downstream of activated mammalian Notch. Nature 377:355-358.

J ennings B, De Celis J F, Delidakis C, Preiss A, Bray S (1995): Role of Notch and achaete-scute complex in the expression of Enhancer of split bHLH proteins. Development 121:3745-3752.

J ohns P R (1977): Growth of the adult goldfish eye. III. Source of the new retinal cells. J Comp Neurol 176:343-357.

J outel A, Corpechot C, Ducros A. Vahedi K, Chabriat H, Mouton P, Alamowitch M, Domenga V, Cécillion M, Maréchal $E$, Maciazek J , Vayssière C, Cruaud C, Cabanis E-A, Ruchoux MM, Weissenbach J , Bach J F, Bousser MG, Tournier-Lasserve E (1996): Notch3 mutations in CADASIL, a hereditary adult-onset condition causing stroke and dementia. Nature 383:707-713.

J ulian D, Korenbrot J I (1996): Cell proliferation in the mature inner nuclear layer of the fish retina. Invest Ophthalmol Vis Sci Suppl 37:692.

Kajishima T (1960): The normal developmental stages of the goldfish, Carassius auratus. J pn J I chthyol 8:20-26.

Kirsche W (1960): Zur Frage der Regeneration des Mittelhirnes der Teleostei. Verh Anat Ges 56:259-270.

Kirsche W, Kirsche K (1961): Experimentelle Untersuchungen zur Frage der Regeneration un Funktion des Tektum opticum von Carassius carassius L. Z Mikrosk Anat Forsch 67:140-182.

Kopan R, Nye J S, Weintraub H (1994): The intracellular domain of mouse Notch: A constitutively activated repressor of myogenesis directed at the basic helix-loop-helix region of MyoD. Development 120:2385-2396.

Lardelli M, Lendahl U (1993): Motch A and motch B-Two mouse Notch homologues coexpressed in a wide variety of tissues. Exp Cell Res 204:364-372.

Lardelli M, Dahalstrand J, Lendahl U (1994): The novel Notch homologue mouse Notch 3 lacks specific epidermal growth factorrepeats and is expressed in proliferating neuroepithelium. Mech Dev 46:123-136.

Levine EM, Hitchcock PF, Glasgow E, Schechter N (1994): Restricted expression of a new paired-class homeobox gene in normal and regenerating adult goldfish retina. J Comp Neurol 348:596-606.

Lewis GP, Erickson PA, Guerin CJ , Anderson DH, Fisher SK (1992): Basic fibroblast growth factor: A potential regulator of proliferation and intermediate filament expression in the retina. J Neurosci 12:3968-3978.

Lewis GP, Guerin CJ , Anderson DH, Matsumoto B, Fisher SK (1994): Rapid changes in the expression of glial cell proteins caused by experimental retinal detachment. Am J Ophthalmol 118:368-376.

Lindsell CE, Shawber CJ , Boulter J, Weinmaster G (1995): J agged: A mammalian ligand that activates Notch1. Cell 80:909-917.

Maier W, Wolburg H (1979): Regeneration of the goldfish retina after exposure to different doses of ouabain. Cell Tissue Res 202:99-118.

Maine E M, Lissemore J L, Starmer WT (1995): A phylogenetic analysis of vertebrate and invertebrate Notch-related genes. Mol Phylogenet Evol 4:139-149.

Menne TV, Klambt C (1994): The formation of commissures in the Drosophila CNS depends on the midline cells and on the Notch gene. Development 120:123-133.

Meyer RL (1978): Evidence from thymidine labeling for continuing growth of retina and tectum in juvenile goldfish. Exp Neurol 59:99-111.

Müller H (1952): Bau und Wachstum der Netzhaut des Guppy 
(Lebistes reticulatus). Zool J ahr Abt Allg Zool Physiol Tiere 63:275324.

Myat A, Henrique D, Ish Horowicz D, Lewis J (1996): A chick homologue of Serrate and its relationship with Notch and Delta homologues during central neurogenesis. Dev Biol 174:233-247.

Nieuwenhuys R, Meek J (1990): The telencephalon of actinopterygian fishes. In J ones EG, Peters A (eds): "Comparative Structure and Evolution of Cerebral Cortex, Part I." Vol. 8. New York: Plenum Press, pp. 31-73.

Nye J S, Kopan R, Axel R (1994): An activated Notch suppresses neurogenesis and myogenesis but not gliogenesis in mammalian cells. Devel opment 120:2421-2430.

Peters LL, Lux SE (1993): Ankyrins: structure and function in normal cells and hereditary spherocytes. Semin Hematol 30:85-118.

Powers MK, Bassi CJ , Rone LA, Raymond PA (1988): Visual detection by the rod system in goldfish of different sizes. Vision Res 28:211221.

Raymond PA, Easter SS J r (1983): Postembryonic growth of the optic tectum in goldfish. I. Location of germinal cells and numbers of neurons produced. J Neurosci 3:1077-1091.

Raymond PA, Rivlin PK (1987): Germinal cells in the goldfish retina that produce rod photoreceptors. Dev Biol 122:120-138.

Raymond PA, Reifler MJ , Rivlin PK (1988): Regeneration of goldfish retina: Rod precursors are a likely source of regenerated cells. J Neurobiol 19:431-463.

Raymond PA, Barthel LK, Rounsifer ME (1992): Immunolocalization of basic fibroblast growth factor and its receptor in adult goldfish retina. Exp Neurol 115:73-78.

Raymond PA, Barthel LK, Curran GA (1995): Developmental patterning of rod and cone photoreceptors in embryonic zebrafish. J Comp Neurol 359:537-550.

Raymond PA, Hitchcock PF (1997): Retinal regeneration: common principles but a diversity of mechanisms. Adv Neurol 72:171-184.

Rebay I, Fehon R, Artavanis-Tsakonas S (1993): Specific truncations of Drosophila Notch define dominant activated and dominant negative forms of the receptor. Cell 74:319-329.

Richter W (1968): Regeneration im Tectum Opticum bei adulten Lebistes reticulatus (Peters 1859) (Poecilidae, Cyprinodontes, Tel eostei). J Hirnforsch 10:173-186.

Richter W, Kranz D (1970a): Die Abhangigkeit der DNA-Synthese in den Matrixzonen des Mesencephalons vom Lebensalter der Versuchstieve (Lebistes reticulatus-Tel eostei). Autoradiographische Untersuchungen. Z Mikrosk Anat Forsch 82:76-92.

Richter W, Kranz D (1970b): Autoradiographische Untersuchungen über die Abhängigkeit des $\mathrm{H}^{3}$-Thymidin-Index vom Lebensalter in den Matrixzonen des Telencephal ons von Lebistes reticulatus (Teleostei). Z Mikrosk Anat Forsch 81:530-554.

Richter W, Kranz D (1977): Uber dei Bedeutung der Zellproliferation fur die Hirnregeneration bei niederen Vertebraten. Autoradiographische Untersuchungen. Verh Anat Ges 71:439-445.

Rogers S, Wells R, Rechsteiner M (1986): Amino acid sequences common to rapidly degraded proteins: the PEST hypothesis. Science 234:364-368.
Sambrook J , Fritsch EF, Maniatis T (1989): “Molecular Cloning: A Laboratory Manual." Cold Spring Harbor, NY: Cold Spring Harbor Laboratory Press.

Schmitz B, Papan C, Campos-Ortega J A (1993): Neurulation in the anterior trunk region of the zebrafish Brachydanio rerio. Rouxs Arch Dev Biol 202:250-259.

Sharma SC (1975). Development of the optic tectum in brown trout. In Ali MA (ed): "Vision in Fishes: New Approaches in Research." NATO Advanced Study Institute, Series A, Life Sciences, Vol. 1. New York: Plenum Press, pp. 411-417.

Sharma SC, Ungar F (1980): Histogenesis of the goldfish retina. J Comp Neurol 191:373-382.

Simpson P (1995): Developmental genetics. The Notch connection. Nature 375:736-737.

Stevenson J A, Yoon MG (1980): Kinetics of cell proliferation in the halved tectum of adult goldfish. Brain Res 184:11-22.

Stevenson J A, Yoon MG (1981): Mitosis of radial glial cells in the optic tectum of adult goldfish.J Neurosci 1:862-875.

Stevenson J A, Yoon MG (1982): Morphology of radial glia, ependymal cells, periventricular neurons in the optic tectum of goldfish (Carassius auratus). J Comp Neurol 205:128-138.

Sullivan SA, Raymond PA (1991): Stimulation of goldfish rod precursor cell proliferation in response to retinal puncture. Invest Ophthalmol Vis Sci Suppl 32:923.

Swiatek PJ , Lindsell CE, del Amo FF, Weinmaster G, Gridley T (1994): Notch1 is essential for postimplantation development in mice. Genes Dev 8:707-709.

Turner DL, Cepko CL (1987): Cell lineage in the rat retina: A common progenitor for neurons and glia persists late in devel opment. Nature 328:131-136.

Tsang SS, Yin X, Guzzo-Arkuran C, J ones VS, Davison A J (1993): Loss of resolution in gel electrophoresis of RNA: A problem associated with the presence of formal dehyde gradients. BioTechniques 14:380381

Uyttendaele H, Marazzi G, Wu G, Yan Q, Sassoon D, Kitajewski J (1996): Notch4/ int-3, a mammary proto-oncogene, is an endothelial cell-specific mammalian Notch gene. Development 122:2251-2259.

Wagner EC, Raymond PA (1991): Müller glial cells of the goldfish retina are phagocytic in vitro but not in vivo. Exp Eye Res 53:583-589.

Weinmaster G, Roberts VJ , Lemke G (1991): A homolog of Drosophila Notch expressed during mammalian development. Development 113:199-205.

Weinmaster G, Roberts VJ, Lemke G (1992): Notch2: A second mammalian Notch gene. Development 116:931-941.

Wharton KA, Yedvobnick B, Finnerty VG, Artavanis-Tsakonas S (1985): opa: A novel family of transcribed repeats shared by the Notch locus and other developmentally regulated loci in D. melanogaster. Cell 40:55-62.

Williams R, Lendahl U, Lardelli M (1995): Complementary and combinatorial patterns of $\mathrm{N}$ otch gene family expression during early mouse development. Mech Dev 53:357-368. 